\title{
Multifunctional polymeric micelles for delivery of drugs and $\operatorname{siRNA}$
}

\section{Aditi M. Jhaveri and Vladimir P. Torchilin*}

Department of Pharmaceutical Sciences, Center for Pharmaceutical Biotechnology and Nanomedicine, Northeastern University, Boston, MA, USA

\section{Edited by:}

Xin Dong Guo, South China

University of Technology, China

\section{Reviewed by:}

Brion William Murray, Pfizer

Worldwide Research and

Development, USA

Krzysztof Szczubialka, Jagiellonian

University, Poland

\section{*Correspondence}

Vladimir P. Torchilin, Department of Pharmaceutical Sciences, Center for Pharmaceutical Biotechnology and Nanomedicine, Northeastern University, 140 The Fenway, \#211/214, Boston, MA, 02115, USA e-mail:v.torchilin@neu.edu
Polymeric micelles, self-assembling nano-constructs of amphiphilic copolymers with a core-shell structure have been used as versatile carriers for delivery of drugs as well as nucleic acids. They have gained immense popularity owing to a host of favorable properties including their capacity to effectively solubilize a variety of poorly soluble pharmaceutical agents, biocompatibility, longevity, high stability in vitro and in vivo and the ability to accumulate in pathological areas with compromised vasculature. Moreover, additional functions can be imparted to these micelles by engineering their surface with various ligands and cell-penetrating moieties to allow for specific targeting and intracellular accumulation, respectively, to load them with contrast agents to confer imaging capabilities, and incorporating stimuli-sensitive groups that allow drug release in response to small changes in the environment. Recently, there has been an increasing trend toward designing polymeric micelles which integrate a number of the above functions into a single carrier to give rise to "smart," multifunctional polymeric micelles. Such multifunctional micelles can be envisaged as key to improving the efficacy of current treatments which have seen a steady increase not only in hydrophobic small molecules, but also in biologics including therapeutic genes, antibodies and small interfering RNA (siRNA). The purpose of this review is to highlight recent advances in the development of multifunctional polymeric micelles specifically for delivery of drugs and siRNA. In spite of the tremendous potential of siRNA, its translation into clinics has been a significant challenge because of physiological barriers to its effective delivery and the lack of safe, effective and clinically suitable vehicles. To that end, we also discuss the potential and suitability of multifunctional polymeric micelles, including lipid-based micelles, as promising vehicles for both siRNA and drugs.

Keywords: micelles, multifunctional, nanocarriers, polymeric, siRNA, targeted

\section{INTRODUCTION}

Nanotechnology is currently at the forefront of drug delivery research, and has provided innovative platforms for management of diseases like cancer, which pose a significant challenge for researchers and patients alike. A variety of nanoscale systems including polymeric and metallic nanoparticles, liposomes, polymeric micelles, nanogels, nanocapsules, dendrimers, carbon nanotubes, nanocrystals and solid lipid nanoparticles, are currently under active investigation for delivery of small molecule drugs as well as therapeutic macromolecules like proteins, peptides, aptamers, DNA and small interfering RNA (siRNA) (Torchilin, 2006; Peer et al., 2007; Wang et al., 2012a). These nanomedicines can successfully overcome many drawbacks of free drugs and therapeutic molecules which include but are not limited to poor solubility, non-selective activity, poor biodistribution and pharmacokinetics (PK), dose-limiting toxicity and also multi-drug resistance (Allen and Cullis, 2004; Jabr-Milane et al., 2008; Sawant et al., 2012). Some of the salient advantages of nanocarriers include their increased drug stability, ability to solubilize hydrophilic and hydrophobic agents, improved PK and biodistribution, tunable payload release, the ability to specifically target their payload to diseased tissues and cells by modification of their surface chemistries, and finally their ability to respond to various internal and external stimuli for "triggered" release to achieve temporal and spatial control over the release of therapeutic payloads (Torchilin, 2006; Peer et al., 2007; Duncan and Gaspar, 2011; Schroeder et al., 2012).

One has to keep in mind, however, that due to the inherent advantages of nanomedicines over conventional therapeutics, the rapid pace of development of nanocarriers and a paucity of detailed systemic toxicology studies on them, it is easy to overlook certain toxicity concerns. It is critical to appreciate that material properties differ significantly at the nanoscale range from those seen in the bulk, with greatly increased surface-to-volume ratios, altered surface chemistry and an increased chemical reactivity (Elsaesser and Howard, 2012). When designing nanocarriers, one needs to address the variables which may lead to potential safety concerns including the material used for construction of the nanocarriers, dose or concentration of the nanocarriers, their size, shape, surface charge, reactivity and solubility (Ai et al., 2011; Elsaesser and Howard, 2012). Due consideration of these variables could enable the development of robust nanosystems with many promising features. 
Although most of the types of nanocarriers listed in this section are capable of providing many of the advantages already mentioned, for the purpose of this review, the discussion is specifically focused on one class of versatile nanocarriers, the polymeric micelles, which are core-shell nano-constructs formed by selfassembly of amphiphilic copolymers. Various modifications for polymeric and lipid-based micelles including those for passive targeting, active targeting and stimuli sensitive release, are discussed with recent examples from the literature. The focus then shifts to micelles which can combine multiple favorable features to form multifunctional polymeric micelles. Since the discovery of RNA interference (RNAi), and its ability to silence virtually any gene, substantial research efforts have been dedicated to the development of suitable carriers to deliver siRNA for cancer therapy (Fire et al., 1998; Shen et al., 2012). To that end, this review also discusses recent progress in siRNA delivery for cancer, challenges facing it and the role of multifunctional polymeric micelles. Finally, we discuss multifunctional micelles which can simultaneously deliver both small molecule drugs and siRNA to tumors.

\section{POLYMERIC MICELLES: BACKGROUND AND RELEVANCE AS THERAPEUTIC NANOCARRIERS FOR CANCER}

Polymeric micelles are spherical, colloidal, supramolecular nanoconstructs (10-100 nm) usually formed from the self-assembly of amphiphilic block copolymers which consist of both hydrophilic and hydrophobic units in an aqueous environment (Yokoyama et al., 1998; Jones and Leroux, 1999; Torchilin, 2001, 2007; Croy and Kwon, 2006). This self-assembly of amphiphilic monomers is entropically favored, and occurs above their critical micelle concentration (CMC) to result in the formation of micelles with a core-shell structure (Torchilin, 2001; Sutton et al., 2007). The hydrophobic portion of the block copolymer forms the core of micelles, while the hydrophilic portion forms the shell or the corona (Figure 1). Generally, micelles of amphiphilic copolymers with low CMC values exhibit greater stability even at low concentrations of the amphiphile in the medium. Increasing the hydrophobicity of the copoloymer reduces the CMC which in turn, increases the micelle stability (Torchilin, 2001; Kabanov et al., 2002). Non-polar molecules are solubilized within the hydrophobic core of micelles; polar molecules get adsorbed on the micelle surface, whereas molecules with intermediate polarity distribute along the surfactant molecules in intermediate positions.

Various amphiphilic copolymers including di-block (A-B), tri-block (A-B-A) as well as graft copolymers can be used to form micelles (Torchilin, 2001). By far, the most frequently utilized hydrophilic block for both di- and tri-block copolymers is poly(ethylene oxide) (PEO) also known as poly(ethylene glycol) (PEG). Other corona forming polymers like poly ( $\mathrm{N}$-vinyl pyrrolidone) (PVP) (Bailly et al., 2012) and poly (N-isopropyl acrylamide) (pNIPAAm) (Kim et al., 2013) have also been reported. A number of different core forming blocks have been reported to date which include poly(propylene oxide) (PPO) (Sharma et al., 2008), poly $\varepsilon$-caprolactone (PCL) (Kanazawa et al., 2013; Laouini et al., 2013), poly (L-lactide) (Xu et al., 2013a), poly(lactide-co-glycolic acid) (PLGA) (Koyamatsu et al., 2013), poly(L-aspartic acid) (pAsp) (Yokoyama et al., 1990; Kagaya et al., 2012), poly(L-histidine) (pHis) (Wu et al., 2013), poly ( $\beta$-amino ester) (PbAE) (Min et al., 2010) and short, hydrophobic phospholipid residues like disteroyl phosphatidyl ethanolamine (DSPE) (Perche et al., 2012; Sawant et al., 2013a; Salzano et al., 2014).

Polymeric micelles exhibit several features that favor their utility for drug delivery applications in cancer. The most important advantage of polymeric micelles is their ability to solubilize poorly water soluble or hydrophobic drugs within their core, thus enhancing their bioavailability. A large number of high throughput screen (HTS) derived hits, lead molecules, development candidates and eventually, marketed drugs share the common characteristic of possessing high hydrophobicities and consequently, low aqueous solubilities (Williams et al., 2013). Even with sophisticated combinatorial chemistry approaches to generate large compound libraries and advanced HTS technologies, it has been difficult to obtain compounds with acceptable water solubility without compromising on their potency. About $40 \%$ of currently marketed drugs and up to $75 \%$ compounds currently under development have been suggested to be poorly water soluble (Di et al., 2009, 2012; Williams et al., 2013). Anti-cancer drugs, which are most often polycyclic compounds, also suffer the same fate. Moreover, because of the intrinsic hydrophobicity of many drugs, parenteral administration becomes problematic and undissolved drug aggregates can lead to embolization of blood

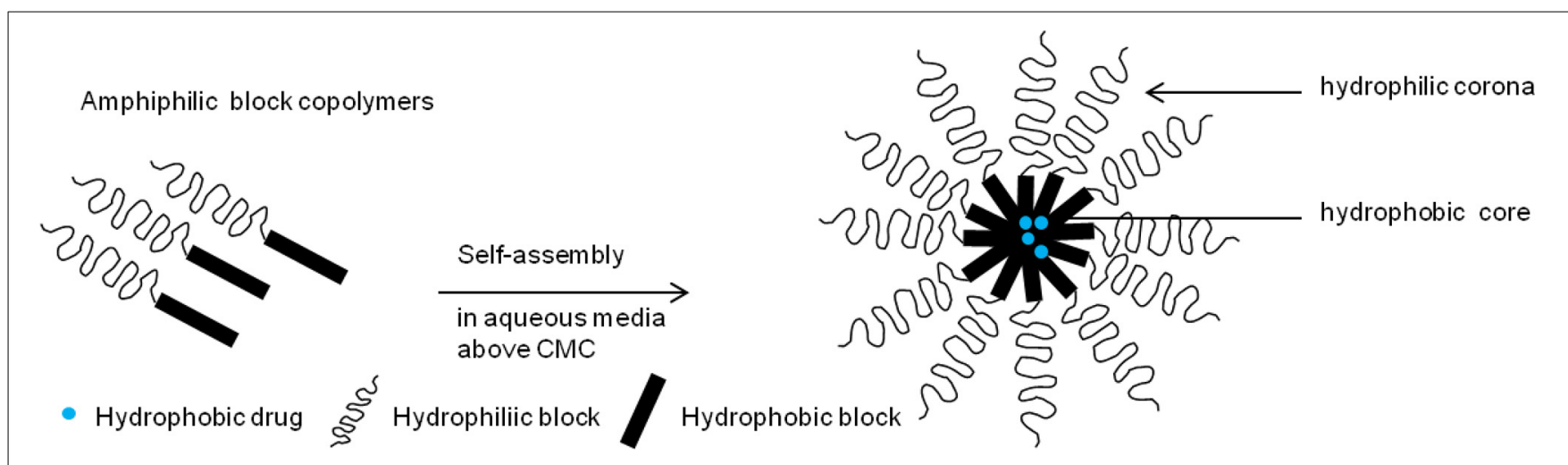

FIGURE 1 | Micelle formation. Drug-loaded polymeric micelle formed from self -assembly of amphiphilic block copolymers in aqueous media. 
capillaries $(\leq 5 \mu \mathrm{m})$ before they reach the tumor (Fernandez et al., 2001). Low solubility coupled with drug excretion and metabolic degradation also results in poor systemic drug concentrations (Torchilin et al., 2003). Polymeric micelles can not only solubilize hydrophobic drugs, but can also protect them from inactivation in the biological milieu and thus increase their bioavailability (Torchilin, 2001). Another important advantage of polymeric micelles is their small size which allows them to circulate in the blood for extended periods by evading the mononuclear phagocytic system (MPS) in the liver. At the same time, their size is large enough to preclude fast renal clearance (Lu and Park, 2013). Longer circulation also allows the micelles to accumulate to a greater extent in areas with a defective or leaky vasculature such as tumors; via the enhanced permeability and retention (EPR) effect, which is the basis of passive targeting (Matsumura and Maeda, 1986; Maeda et al., 2000). Polymeric micelles possess a high structural stability due to the interactions between polymeric chains in the core-forming hydrophobic blocks, which allows them to retain encapsulated drugs and also be stable upon dilution in the body (Torchilin, 2002). Additional advantages of micelles include reduced side effects of the encapsulated drug, easy and reproducible scale-up, the ability to slow down opsonization and the possibility of longer circulation times when hydrophilic moieties such as PEG, that provide an effective steric barrier, are incorporated in the micelles. Finally, their surface can be modified with various ligands using different surface chemistries to produce targeted micelles (Torchilin, 2002; Sawant and Torchilin, 2010; Lu and Park, 2013).

\section{PASSIVE TARGETING OF POLYMERIC MICELLES AND MODIFICATION FOR LONGEVITY}

Passive targeting of nanocarriers including polymeric micelles relies on the tumor microenvironment. Their accumulation proceeds mainly via the EPR effect (Maeda et al., 2000). Tumor vasculature grows aberrantly to meet the ever-increasing nutrient and oxygen demand of the growing tumor, which leaves the endothelial cells poorly aligned with large fenestrations between them (Jain, 1987; Folkman, 1995; Roberts and Palade, 1997; Hobbs et al., 1998). This architectural abnormality and the production of vascular permeability factors like nitric oxide, bradykinin, matrix metalloproteinases (MMPs) and vascular endothelial growth factor (VEGF) make the tumor blood vessels highly permeable (Wu et al., 1998; Fang et al., 2011). The growing tumor cells also compress the lymph vessels, particularly in the central portion of the tumor, causing them to collapse, resulting in poor lymphatic drainage from tumors (Padera et al., 2004). Both these phenomena-the increased vascular permeability and the defective lymphatic drainage not only allow leakage of blood plasma components and nanoparticles (e.g., micelles) into tumor tissues, but also allow them to be retained there (Maeda et al., 2000; Iyer et al., 2006). This phenomenon is termed the EPR effect (Matsumura and Maeda, 1986) (Figure 2).

Although the EPR effect plays a crucial role in the accumulation of polymeric micelles, other factors such as the size and surface characteristics of micelles also determine the effectiveness of passive targeting (Torchilin, 2007; Ganta et al., 2008). Longevity of the nanocarrier in circulation is very important for passive targeting (Torchilin and Trubetskoy, 1995; Torchilin, 2006; Petros and Desimone, 2010). Generally, longevity is imparted to polymeric micelles by flexible, hydrophilic polymer coatings like PEG which can be grafted onto their surface (Torchilin and Trubetskoy, 1995; Torchilin, 2006). PEG acts as a steric barrier and is effective in preventing rapid opsonization of micelles by the MPS, lengthening their circulation time in the blood. This, in turn, gives micelles a better chance of extravasation through the leaky vasculature and slow accumulation in the tumor via

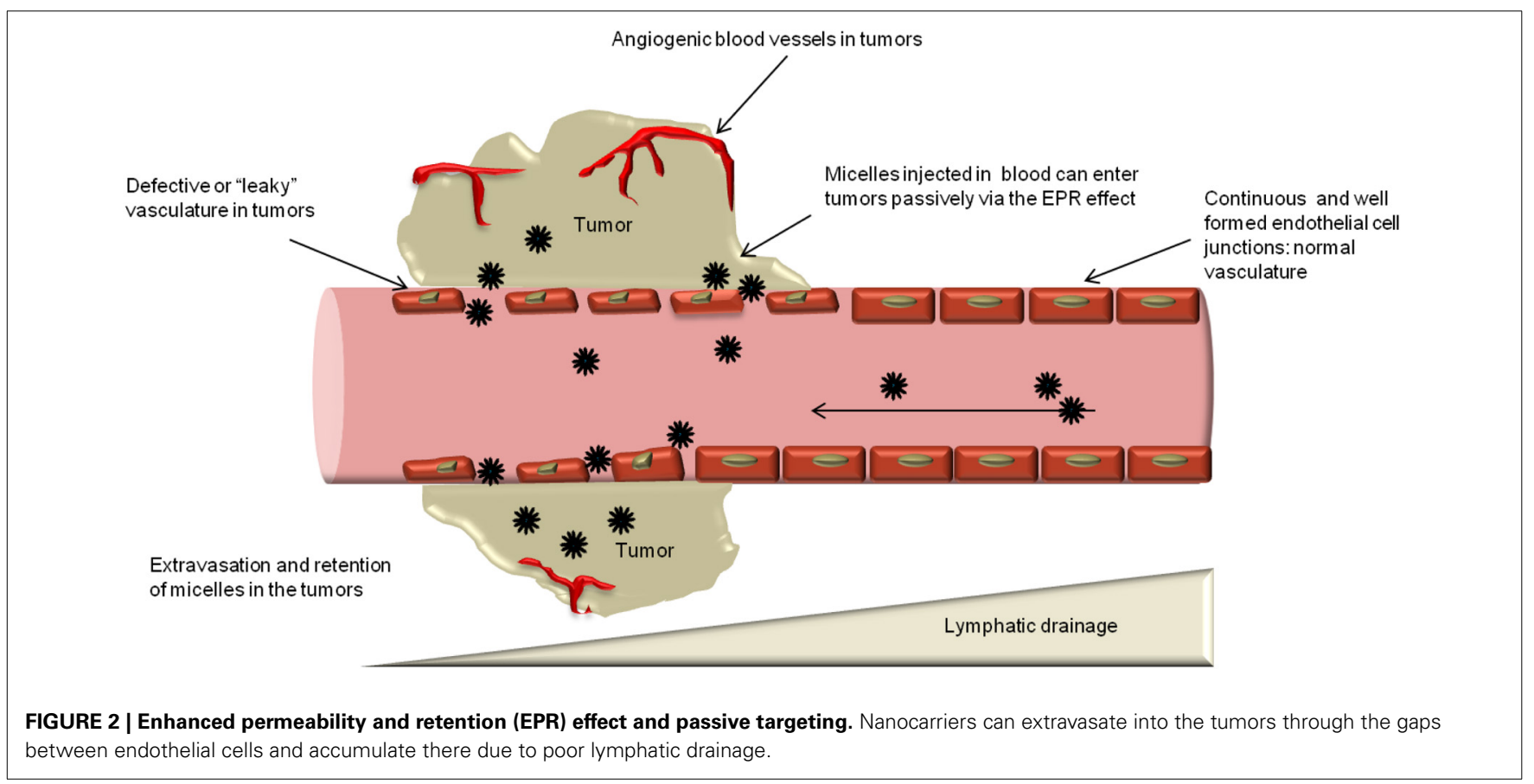


the EPR effect (Mahmud et al., 2007; Torchilin, 2011). The steric barrier provided by PEG shields the surface charge of micelles, hinders their interaction with blood components and limits adsorption of plasma proteins on their surface (Torchilin, 2006).

The size of polymeric micelles also has a crucial role in the EPR effect-mediated accumulation as discussed in the previous section. Tumor vasculature cutoff sizes can vary between tumors $(200-800 \mathrm{~nm})$, and determine the diffusion and accumulation of molecules within the tumor interstitium (Yuan et al., 1995; Torchilin, 2011). The benefit of small sized polymeric micelles, which are well below the cutoff limit for most tumors, ensures that they remain in circulation for longer intervals without being taken up by MPS and eventually enter the tumor vasculature through the EPR effect. Some examples of polymeric micelle formulations exploiting the passive targeting effect are listed in Table 1.

Table 1 | Passively targeted therapeutic preparations of polymeric micelles.

\begin{tabular}{|c|c|c|}
\hline $\begin{array}{l}\text { Micelle } \\
\text { components/formulation }\end{array}$ & Drug(s) & References \\
\hline \multicolumn{3}{|l|}{ PRE-CLINICAL } \\
\hline PEG2000-PE & Docetaxel & Tong et al., 2012 \\
\hline \multirow[t]{2}{*}{ PEG2000-PE/Nitamin E } & $\begin{array}{l}\text { Paclitaxel and } \\
\text { curcumin }\end{array}$ & Abouzeid et al., 2014 \\
\hline & $\begin{array}{l}\text { Paclitaxel and } \\
\text { Elacridar }\end{array}$ & Sarisozen et al., 2012 \\
\hline $\begin{array}{l}\text { PEG2000-PE/Hydrogenated } \\
\text { phosphatidylcholine } \\
\text { (PEG200-PE/HSPC) }\end{array}$ & Doxorubicin & Wei et al., 2012b \\
\hline $\begin{array}{l}\text { Adamantine terminated PEG } \\
\text { and } \beta \text {-cyclodextrin based } 7 \\
\text { armed poly(L-glutamic acid) } \\
\text { (mPEG-Ad@ } \beta \text {-CD-7PLGA/CDDP) }\end{array}$ & CDDP & Yong et al., 2013 \\
\hline Stearate grafted dextran & Doxorubicin & Du et al., 2010 \\
\hline mPEG-b-poly(D,L-lactide) & Docetaxel & Li et al., 2012d \\
\hline Pluronic P123/F127 & Paclitaxel & $\begin{array}{l}\text { Zhang et al., 2010, } \\
2011 \mathrm{~b}\end{array}$ \\
\hline \multicolumn{3}{|l|}{ CLINICAL } \\
\hline $\begin{array}{l}\text { Genexol@-PM, mPEG-PDLLA } \\
\text { (Ph-IV/approved in Korea) }\end{array}$ & Paclitaxel & Kim et al., 2004 \\
\hline NK105, PEG-p(Asp) (Ph-III) & Paclitaxel & $\begin{array}{l}\text { Hamaguchi et al., 2007; } \\
\text { Kato et al., } 2012\end{array}$ \\
\hline $\begin{array}{l}\text { SP1049C, Pluronic L61 and } \\
\text { F127 (Ph-III) }\end{array}$ & Doxorubicin & $\begin{array}{l}\text { Danson et al., 2004; } \\
\text { Valle et al., } 2011\end{array}$ \\
\hline NK012, PEG-P(Glu)-SN38 (Ph-II) & $\mathrm{SN}-38$ & $\begin{array}{l}\text { Matsumura et al., 2004; } \\
\text { Koizumi et al., } 2006\end{array}$ \\
\hline $\begin{array}{l}\text { NC-6004, PEG-P(Glu)-cisplatin } \\
\text { (Ph-I/II) }\end{array}$ & Cisplatin & Plummer et al., 2011 \\
\hline NK911, PEG-P(Asp)-DOX (Ph-II) & Doxorubicin & Matsumura et al., 2004 \\
\hline $\begin{array}{l}\text { NC-4016, PEG-P(Glu) DACHPt } \\
(\mathrm{Ph}-\mathrm{I})\end{array}$ & $\mathrm{DACHP} \mathrm{t}^{\mathrm{b}}$ & $\begin{array}{l}\text { Cabral et al., 2005, } \\
2007\end{array}$ \\
\hline
\end{tabular}

DACHPt, Dichloro-(1,2-diaminocyclohexane) platinum (II), ${ }^{\mathrm{b}} C D D P$, cisdichlorodiamine platinum (II).
Although passive targeting is useful clinically, it is not without its drawbacks. Major impediments to passive targeting include the inherent tumor heterogeneity wherein cutoff sizes could vary between tumors, and even within the same tumor. The vasculature may exhibit varying porosities and consequently different permeabilities (Monsky et al., 1999; Prabhakar et al., 2013). The implicit diversity in tumors may lead to some areas not showing the characteristic EPR effect and some tumor vessels may not be "leaky" which leads to heterogeneous extravasation and delivery of drug vehicles (Yuan et al., 1995, 1996; Fang et al., 2011). In addition, nanocarriers such as polymeric micelles that are modified with a biocompatible surface coating of the hydrophilic PEG face the so called "PEG dilemma" since PEG may interfere with their endosomal escape and intracellular uptake into tumors (Hatakeyama et al., 2011). Also, only passive accumulation of micelles based on the EPR effect cannot ensure their effective delivery to molecular targets within tumors (Mahmud et al., 2007). It is thus clear that passive targeting alone may not suffice and additional approaches like active targeting which enable more selective and robust target recognition may need to be utilized (Torchilin, 2006; Peer et al., 2007).

\section{ACTIVE TARGETING OF POLYMERIC MICELLES}

Tumor cells and/or tumor vasculature frequently show increased expression of certain molecules (antigens or receptors) which are generally not expressed, or present at low levels on the surface of normal cells and surrounding normal tissues (Park et al., 2008; Kamaly et al., 2012). Active targeting exploits this feature of cancer cells to allow selective accumulation of anti-cancer therapeutics in the tumor tissue, tumor cells or intracellular organelles of the cell (Nie et al., 2007). Polymeric micelles can be functionalized for active targeting by chemically modifying their surface with targeting ligands that show a strong specificity for antigens or receptors over-expressed on cancer cells (Torchilin, 2007; Park et al., 2008) (Figure 3). Usually, the targeting ligands can be attached to the water-exposed free termini of hydrophilic blocks (PEG) of the micelles, so that they extend above the PEG brush and avoid steric hindrance when binding to their target receptors (Torchilin, 2001, 2007). Actively targeted polymeric micelles decrease side-effects of drugs by allowing preferential accumulation in diseased cells and also facilitate cellular uptake by receptor-mediated endocytosis (Park et al., 2008; Danhier et al., 2010). Active targeting especially benefits intracellular delivery of macromolecules like DNA, siRNA and proteins. The anti-tumoral efficacy of actively targeted delivery vehicles derives from their enhanced cellular internalization rather than just an increased tumor accumulation (Kirpotin et al., 2006).

A wide variety of ligands have been investigated to date for active targeting of polymeric micelles. Some of the commonly used targeting ligands include antibodies and their fragments (Jin et al., 2011a; Sawant et al., 2013a; Zhao et al., 2013), peptides (Gülçür et al., 2013; Miura et al., 2013; Chung et al., 2014), proteins (Fonge et al., 2012; Riehle et al., 2013; Sawant et al., 2013b), aptamers (Xu et al., 2013b), sugar moieties (Sun et al., 2011a; Yang et al., 2011; Yu et al., 2013b), and small molecules like folate (Qiu et al., 2013; Yang et al., 2013). 


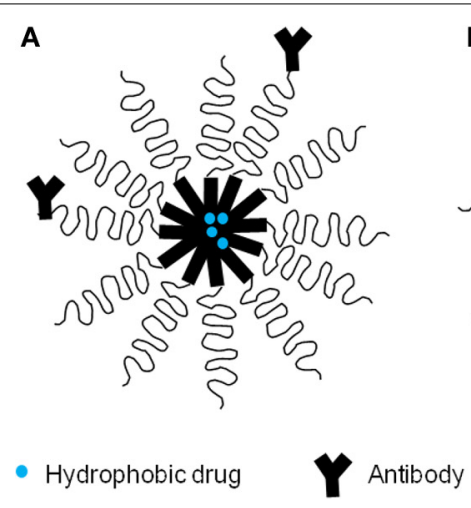

A

Hydrophobic dru

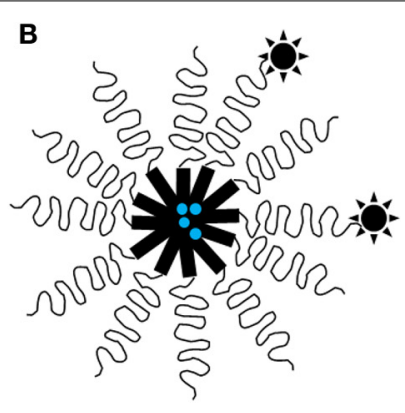

Receptor targeted ligands (transferrin folate)

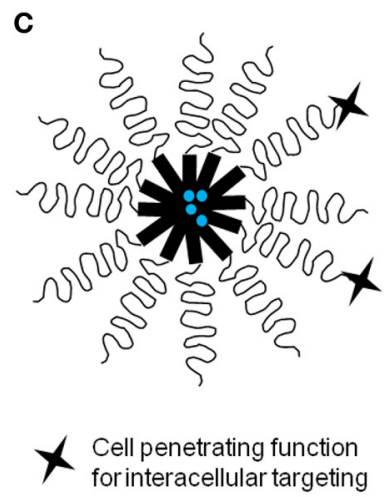

FIGURE 3 | Drug-loaded polymeric micelles with various targeting functions. (A) Antibody-targeted micelles (B) ligand-targeted micelles (C) Micelles with cell-pentrating function.

Antibodies have been the most popular targeting ligands for polymeric micelles to date because of the diversity of their targets and the specificity of their interaction (Torchilin, 2004). Over the years, antibody engineering technologies have enabled the development of murine, chimeric, humanized and human monoclonal antibodies (mAbs) as well as antibody fragments (e.g., Fab, scFv, diabodies, triabodies and single-domain antibodies) (Holliger and Hudson, 2005; Weiner, 2007). Poly(ethylene)glycolphosphatidyl ethanolamine (PEG2000-PE) micelles loaded with doxorubicin (DOX) and targeted with the anti-nucleosome mAb $2 \mathrm{C} 5$, which is specific for cancer cells were shown to be effective in a DOX-resistant ovarian cancer cell spheroid model. The 2C5 targeted DOX micelles showed better uptake and penetration and also induced greater cell death in spheroids compared to free DOX and non-targeted DOX micelles (Perche et al., 2012). In another example, anti-Her2 antibody Fab fragment was conjugated to temperature sensitive block copolymer micelles made from poly(N-isopropylacrylmide-co-N,N'dimethylacrylamide) $)_{118}-b$-poly(D,L-lactide) 71 (Li et al., 2012b). The dual function of temperature sensitive and Her2 targeted immunomicelles showed significant in vitro toxicity and accumulation, high in vivo stability, greater intra-tumoral accumulation and significant tumor inhibition in a Her2 over-expressing mouse model of gastric cancer compared to various controls ( $\mathrm{Li}$ et al., $2012 b)$. Although very popular as targeting ligands, antibodies do face some challenges. These include their large size $(\sim 150 \mathrm{kDa})$ which results in limited ligand densities on micelles, potential immunogenicity which may lead to rapid clearance, stability considerations and engineering challenges during scale-up manufacturing (Goldenberg and Sharkey, 2012; Kamaly et al., 2012). Finally the success of immunomicelles largely depends on the target antigen being truly "tumor-specific" so as to avoid side-effects (Firer and Gellerman, 2012).

Proteins and peptides have also been used extensively as targeting ligands for polymeric micelles. The transferrin receptor (TfR) is over-expressed in many cancers and offers an attractive option for the development of transferrin-targeted nanocarriers (Singh, 1999). Polymeric micelles may be modified either with endogenous ligand transferrin (Tf) or antibodies against TfR (Torchilin, 2006). Sawant et al. showed that drug (R547)loaded PEG2000-PE micelles modified with Tf showed a greater interaction with TfR over-expressing A2780 ovarian carcinoma cells in vitro at $48 \mathrm{~h}$ compared with free drug and non-modified micelles. Tf-targeted micelles also exhibited greater cytotoxicity in vitro and a significant tumor growth inhibition in mice vs. the drug-loaded, non-targeted micelles (Sawant et al., 2013b). Other protein ligands like tumor necrosis factor related apoptosis inducing ligand (TRAIL), which binds to death receptors up-regulated in cancer cells to induce apoptosis (Skidan et al., 2009; Lee et al., 2011a; Riehle et al., 2013) and epidermal growth factor (EGF) which targets the EGF receptors over-expressed in many cancers (Zeng et al., 2006; Fonge et al., 2012) are also utilized for modification of polymeric micelles for active targeting.

Peptides are used as targeting ligands due to their small size, lower immunogenicity compared to proteins, better stability in vivo, relative ease of conjugation to polymeric micelles and lower costs (Kamaly et al., 2012). The arginine-glycine-aspartic acid (RGD) tri-peptide which targets integrin receptors $\left(\alpha_{v} \beta_{3}\right.$, $\alpha_{v} \beta_{5}$ ) has been widely investigated. Recently, Miura et al. reported polymeric micelles self-assembled from PEG- $b$-poly $(\mathrm{L}$-glutamic acid) and (1,2-diaminocyclohexane)platinum(II) (DACHPt), the parent complex of oxaliplatin, targeted with cyclic RGD (cRGD) for delivery of anti-cancer drugs to glioblastoma (Miura et al., 2013). Intravital confocal laser scanning microscopy (IVCLSM) revealed that the cRGD micelles accumulated rapidly and had a higher permeability within the tumor parenchyma compared to the non-targeted micelles. The rapid internalization of these micelles also led to significant antitumor effects in an orthotopic mouse model of U87 MG human glioblastoma compared to the controls (Miura et al., 2013). PEG2000$\mathrm{PE}$ micelles were modified with vasoactive intestinal peptide (VIP) to target VIP receptors over-expressed in breast cancer (Dagar et al., 2012; Gülçür et al., 2013). Other peptides like Lyp-1 (Cys-Gly-Asn-Lys-Arg-Thr-Arg-Gly-Cys) which targets the p32 receptors (p32/gC1qR) over-expressed on some tumor cells (Wang et al., 2012c), cell-penetrating peptides like 
trans-activating transcriptional transactivator (TAT) from HIV1 (Kanazawa et al., 2012; Taki et al., 2012) and octreotide which targets somatostatin receptors have also been used to modify polymeric micelles (Xu et al., 2013a). Some groups have reported the development of peptides with affinities for molecular targets over-expressed on different types of tumor cells or tumor vasculature using the phage-display technology (Mori, 2004; Petrenko, 2008). Such peptides have been utilized successfully to modify polymeric micelles for cancer-specific targeting (Wang et al., 2010c; Qian et al., 2013).

Small molecules are particularly attractive as targeting ligands for polymeric micellar carriers due to inherent advantages like a small size, ability to attain higher ligand densities over antibodies, reproducible and scalable manufacturing, less immunogenicity when compared to macromolecules, ease of conjugation using simple chemical methods and the large diversity of such ligands (Kamaly et al., 2012). Folate receptors (FR) are over-expressed in a number of cancers, and hence folate is widely used as a targeting ligand for cell-specific delivery in these cancers (Leamon and Low, 1991; Sudimack and Lee, 2000). DOX-loaded and folatetargeted poly(2-ethyl-2-oxazoline)- $b$-PCL micelles (FA-PEOzPCL) showed better cellular uptake and exhibited lower $\mathrm{IC}_{50}$ values in FR over-expressing cells compared to non-targeted micelles. In vivo, they exhibited better anti-tumor efficacy and reduced toxicity compared to free DOX (Qiu et al., 2013). Other small molecules like biotin (Lin et al., 2013), galactose (Zhong et al., 2013), and mannose (Freichels et al., 2012) have also been reported for surface modification of polymeric micelles.
Aptamers-oligonucleotides which have the ability to fold into defined 3D structures and bind with high affinity and specificity to their target molecules (proteins, peptides or small molecules) are also gaining momentum as targeting ligands (Zhang et al., 2011c). A10 aptamer (Apt), which recognizes the extracellular domain of the prostate-specific membrane antigen (PSMA), was conjugated to unimolecular DOX loaded micelles consisting of a H40 dendritic core, an inner shell of hydrophobic PLA and an outer hydrophilic PEG shell (H40-PLA-PEG-Apt) for targeted prostate cancer therapy(Xu et al., 2013b). The Apt-targeted micelles exhibited a significantly higher uptake and hence cytotoxicity over the non-targeted micelles. In vivo, they also resulted in a much higher DOX uptake in tumors than non-targeted micelles or free DOX (Xu et al., 2013b).

Table 2 lists some examples of actively targeted polymeric micelles.

\section{STIMULI-RESPONSIVE POLYMERIC MICELLES}

An added sophistication to selective delivery of polymeric micelles can be brought about by utilizing certain cues inherently characteristic of the tumor microenvironment (intrinsic) or by applying certain stimuli to this region from outside the body (extrinsic) (Torchilin, 2009). Polymeric micelles can be engineered so as to respond to various intrinsic or extrinsic stimuli of physical, chemical or biochemical origins to achieve spatial and temporal control over the release of therapeutic payloads (Cheng et al., 2013). "Environmentally-responsive" or "smart" polymeric micelles can release their therapeutic payloads by undergoing structural modifications in response to the stimulus.

\begin{tabular}{|c|c|c|c|c|}
\hline $\begin{array}{l}\text { Poly(D,L-lactic-co-glycolic } \\
\text { acid)-PEG }\end{array}$ & Doxorubicin & HAb18(Fab') ${ }_{2}$ & Hepatocellular carcinoma cells & Jin et al., 2011a \\
\hline \multirow[t]{2}{*}{ PEG2000-PE } & Curcumin and Doxorubicin & Anti-GLUT1 antibody & GLUT1 receptors & Abouzeid et al., 2013 \\
\hline & DM-PIT1 analogs & TRAIL & Death receptors on cancer cells & Riehle et al., 2013 \\
\hline $\begin{array}{l}\text { Poly(L-glutamic } \\
\text { acid)-g- } \alpha \text {-tocopherol/PEG }\end{array}$ & Docetaxel and Cisplatin & Cyclic(RGD)fk & $\alpha_{V} \beta_{3}$ integrins & Song et al., 2014 \\
\hline DSPE-PEG2000 & Curcumin & $\begin{array}{l}\text { Vasoactive intestinal } \\
\text { peptide (VIP) }\end{array}$ & VIP receptors & Gülçür et al., 2013 \\
\hline Poly(lactic acid)-PEG & Docetaxel & Folic acid & Folate receptors & Hami et al., 2014 \\
\hline $\begin{array}{l}\text { Cholesterol modified glycol } \\
\text { chitosan (CHGC) }\end{array}$ & Doxorubicin & Galactose & Asialoglycoprotein receptors & Yu et al., 2014 \\
\hline $\begin{array}{l}\text { Azide (N3)-PEG-poly( } \varepsilon^{-} \\
\text {caprolactone) }\end{array}$ & TGX-221 (PI3K inhibitor) & PSMA a10 aptamer & Prostate specific membrane antigen & Zhao et al., 2012 \\
\hline
\end{tabular}

DM-PIT-1, N-l(2-hydroxy-5-nitrophenyl)aminolcarbonothioyl-3,5-dimethylbenzamide; PEO-PPO-PEO, poly(ethylene oxide)-co-poly(propylene oxide)-co-(polyethylene oxide). 
The response may result in disintegration/destabilization, isomerization, polymerization or supramolecular aggregation of micelles (Fleige et al., 2012). The commonly encountered intrinsic stimuli in tumors include low $\mathrm{pH}$, redox status of the cell, and the presence of certain over-expressed enzymes while the extrinsic stimuli include magnetic fields, light (UV, infrared or visible) and ultrasound. Hyperthermia is a stimulus that could be either intrinsic or extrinsic - intrinsically from inflammation, or extrinsically upon application of ultrasound or alternating magnetic fields in conjunction with magnetic nanoparticles which release heat (Torchilin, 2009).

The acidic $\mathrm{pH}$ in tumors results from extensive hypoxia and cell death which leads to production and accumulation of lactic acid (Tannock and Rotin, 1989). The $\mathrm{pH}$ in tumors is $\sim 6.5$ compared to $\sim 7.4$ in the normal tissues and drops even further in the intracellular organelles like endosomes ( $\sim-6)$ and lysosomes ( 4-5) (Gerweck and Seetharaman, 1996; Casey et al., 2010). These $\mathrm{pH}$-gradients have been exploited successfully to design $\mathrm{pH}$-sensitive polymeric micelles which can release their therapeutic payloads when they encounter a change in the $\mathrm{pH}$ of their microenvironment. A number of strategies have been explored to design $\mathrm{pH}$-sensitive micelles, which have been reviewed elsewhere (Felber et al., 2012; Liu and Zhang, 2012; Chen et al., 2013; Li et al., 2013d).

The redox potential in cancer cells is elevated (100-1000-fold higher) due to the high intracellular concentration $(2-10 \mathrm{mM})$ of glutathione tripeptide ( $\gamma$-glutamyl-cysteinyl-glycine) (GSH) compared to its concentration $(2-10 \mu \mathrm{M})$ outside cells (Saito et al., 2003). Moreover, tumor cells also show elevated GSH levels compared to normal cells. Polymeric micelles with disulfide bonds have been designed to hold the cargo (drugs, siRNA, DNA or proteins) under normal conditions and release it upon destabilization in the reducing conditions found inside cancer cells that can convert disulfide linkages to thiols (Torchilin, 2009; Wei et al., 2012a). The disulfide linkages can be incorporated in the hydrophobic backbone (Li et al., 2013e), at the junction of hydrophobic and hydrophilic blocks (Li et al., 2012a), or by incorporating reduction sensitive cross-links in the micelle core (Li et al., 2011), shell (Koo et al., 2012) or the core-shell interface (Hossain et al., 2010). siRNA has also been delivered effectively using redox-sensitive micelles (Matsumoto et al., 2009; Musacchio et al., 2010). Gradients of oxygen tension within the tumors can be exploited to design hypoxia sensitive nanocarriers. In one of the first studies of its kind, Perche, Biswas et al. reported a hypoxia activated nanocarrier for siRNA to achieve the down-regulation of a model gene (GFP) in vitro and in vivo (Perche et al., 2014). Here, azobenzene was used as a hypoxia-responsive, bio-reductive linker for hypoxia-targeted delivery of siRNA from PEGylated nanopreparations upon PEG cleavage. The nanocarrier consisted of PEG2000, azobenzene, polyethyleneimine (PEI $1.8 \mathrm{kDa}$ ) and 1,2-dioleyl-sn-glycero-3phosphoethanolamine (DOPE) units, known as PAPD. The azobenzene was linked to PEG2000 (for stability in circulation) at one end and to a PEI-DOPE conjugate (to complex siRNA) at the other end to form the nanocarrier. PAPD showed a hypoxiadependent cellular uptake and accumulation and resulted in $30-40 \%$ GFP down-regulation in a number of GFP expressing cell lines under hypoxic conditions. In A2780/GFP tumor bearing mice, GFP down-regulation was detected by ex-vivo imaging (24\%) and flow cytometry (32\%) after intravenous (i.v.) administration of PAPD/siRNA which correlated well with the in vitro results (Perche et al., 2014).

Enzyme-sensitive micelles take advantage of the altered expression profile of certain enzymes in cancer or other diseases to deliver therapeutics to the desired targets (Mura et al., 2013). Enzyme sensitive moieties can be used to modify the polymers (main chain or side groups), which upon recognition by the enzyme cause structural changes in the micelles. Alternatively, these moieties may also be recognized by a product of the enzymatic reaction. Another option is to modify the micelle surface with peptides or oligonucleotides that can cause physical changes in the micelles upon enzymatic transformation (De La Rica et al., 2012; Hu et al., 2012). The enzymes most frequently dysregulated in cancer include hydrolases (proteases, lipases and glycosidases), metabolic enzymes including those involved in glycolysis and fatty acid synthesis and oxidoreductases (De La Rica et al., 2012). The matrix metalloproteinase (MMP) family of enzymes (MMP2 and 9 in particular) is primarily linked to cancer progression and metastasis. To that end, polymeric micelles containing MMPsensitive linkers have been reported for tumor-specific delivery of drugs and siRNA in response to the over-expressed MMPs (Li et al., 2013b; Zhu et al., 2014). DOX-loaded polysaccharidelecithin reverse micelles, with a triglyceride outer shell that was sensitive to hydrolysis by lysosomal acid lipase, were reported to overcome multi-drug resistance (Su et al., 2013). Enzymeresponsive polyion complex micelles (PICs) that disintegrate in response to phosphatase and acetylcholinesterase respectively have been developed by Zhang and co-workers (Wang et al., 2010a; Xing et al., 2012).

Among the extrinsic stimuli, ultrasound has been investigated widely as a trigger for drug release from polymeric micelles (Husseini and Pitt, 2008b; Husseini et al., 2009; Mohan and Rapoport, 2010; Rapoport et al., 2010).Ultrasound refers to the application of pressure waves above a frequency of $20 \mathrm{kHz}$ to spatially and temporally control drug release (Husseini and Pitt, 2008a). Pluronic ${ }^{\circledR}$ micelles have been investigated extensively for ultrasound-triggered delivery of both drugs as well as nucleic acids (Chen et al., 2006; Husseini et al., 2013). While low frequency ultrasound $(20-100 \mathrm{kHz})$ can penetrate deeper into the body tissues than high frequency ultrasound ( $1-3 \mathrm{MHz})$, it cannot be focused as well (Rapoport, 2012). In vitro, ultrasound can perturb the micelle structure and cause the release of therapeutic payloads due to cavitation. In vivo, this mechanical effect of ultrasound may also be accompanied by local hyperthermia, which could lead to increased micelle extravasation and accumulation in the tumor tissues (Rapoport, 2012). Ultrasoundsensitive, paclitaxel (PTX)-loaded block copolymer micelles of methoxy PEG and poly(D,L-lactide) (MePEG-b-PDLLA) resulted in increased PTX accumulation and subsequently increased cytotoxicity in both drug-sensitive and drug-resistant (P-glycoprotein expressing) cell lines (Wan et al., 2012).

Magnetic field has also been explored as an extrinsic stimulus for polymeric micelles. Micelles can be loaded with drugs as well as superparamagnetic iron oxide nanoparticles (SPIONS) 
like magnetite $\left(\mathrm{Fe}_{3} \mathrm{O}_{4}\right)$ or maghemite $\left(\mathrm{Fe}_{2} \mathrm{O}_{3}\right)$ which allows them to be manipulated under the guidance of an externally applied permanent magnet or an alternating magnetic field to control either the drug release, result in a temperature increase or even both when used alternately (Torchilin, 2009; Mura et al., 2013). Wang et al. reported SPION-loaded poly (D,L-lactide)- $b$-mPEG (mPEG-PLA) micelles coated with chitosan and PEI (CP-magmicelles) for delivery of plasmid DNA and magnetic resonace imaging (MRI). The CP-mag micelles had high MRI relaxivity, showed significantly higher transfection efficiencies compared to PEI or lipofectamine and a single injection of plasmid-bearing CP-mag micelles could express genes in vivo for at least 1 week (Wang et al., 2012b). In another study, folate-targeted, DOXloaded magnetic nanomicelles made from Pluronic F127 and PLA showed enhanced accumulation in vitro and in vivo in the presence of an external magnetic field (Huang et al., 2012). Magnetic heating was utilized to trigger drug release from PEG- $b$-PCL micelles loaded with iron oxide nanoparticles and DOX. The release of DOX was faster when the micelles were heated above the melting point of their PCL cores (Glover et al., 2013).

Temperature is one of the most widely investigated stimuli for drug delivery and has been extensively explored for cancer treatment. Thermo-responsive micelles are constructed from thermo-sensitive blocks which can undergo a sharp change in phase that destabilizes the micelles and triggers the release of the drug (Torchilin, 2009; Mura et al., 2013). The most widely used polymer for such micelles is poly( $\mathrm{N}$-isopropyl acrylamide) (PNIPAAm), which exhibits a lower critical solution temperature (LCST) of $32^{\circ} \mathrm{C}$. It undergoes a phase transition from hydrophilic (coil) to hydrophobic (globule) state above its LCST. The LCST can be varied by controlling the hydrophilic and hydrophobic polymer composition (Dimitrov et al., 2007; Kang et al., 2008). Yang et al. reported camptothecin (CPT)-loaded micelles formed from comb-like copolymers of mPEG blocks and hydrophobic polyacrylate (PA) backbones, with thermosensitive PNIPAAm graft chains (mPEG- $b$-PA- $g$-PNIPAAm).The micelles showed a thermo-responsive hydrophilic to hydrophobic phase transition with a LCST from 40 to $45^{\circ} \mathrm{C}$. CPT release from the micelles was continuous, without an initial burst release, and was accelerated above the LCST. The CPT- loaded thermo-responsive micelles were selectively cytotoxic to cancer cells while avoiding toxicity to normal cells, unlike the free drug (Yang et al., 2014). Prabharan et al. reported thermo-sensitive poly ( $N$-vinylcaprolactam)- $b$ PEG micelles loaded with 5-fluorouracil (5-FU) and coupled with folate as a targeting agent to target FR over-expressing cancer cells and showed controlled drug release at $37^{\circ} \mathrm{C}$ (Prabaharan et al., 2009).

Light-sensitive micelles can utilize ultraviolet (UV), visible or near infrared (NIR) light to trigger drug release with excellent remote spatio-temporal control (Mura et al., 2013). Some recent reviews have discussed the design principles of such photoresponsive micelles and mechanisms of photo-induced drug release from delivery carriers (Schumers et al., 2010; Fomina et al., 2012; Gohy and Zhao, 2013). Photo-responsive groups can be incorporated within the micelle core, corona or at the core-shell interface in the design of light-sensitive micelles (Gohy and Zhao, 2013). Generally, the chromophores or light-sensitive moieties are incorporated within the core, or conjugated to it (Oerlemans et al., 2010). Azobenzenes and their derivatives comprise the most commonly encountered reversible photo-responsive groups. They undergo a reversible trans-cis photoisomerization upon UV light irradiation which converts the apolar trans isomer to a polar cis isomer, while visible light reverses this isomerization (Zhao, 2007). To develop photo-sensitive micelles with increased dispersion stability, Boissiere et al. reported flowerlike micelles containing hydrophobically modified PNIPAAm with multiple azo-benzene segments incorporated into the main chain (Boissiere et al., 2011). The micelles responded to both UV and visible light by undergoing reversible trans-cis isomerization and remained well dispersed even above the LCST of PNIPAAm due to the multiple chain-folding of multi-azoPNIPAAm chains caused by aggregation of azobenzene moieties (Boissiere et al., 2011). Recently, spiropyran- initiated hyperbranched polyglycerol (SP- $h b$-PG) micelles were reported, which responded to UV/visible light and could dissociate due to conversion of the hydrophobic chromophore SP to zwitterionic and hydrophilic merocyanine (ME) (Son et al., 2014). Chromophores like coumarin, o-nitrobenzyl, stilbene, dithienylethene and 2diazo-1,2-napthoquinone (DNQ) have also been employed in light-responsive micelles, which can respond either to UV/visible or NIR irradiation to undergo structural or phase changes and trigger the drug release from micelles (Chen et al., 2011; Jin et al., 2011b; Menon et al., 2011; Liu et al., 2012; Cao et al., 2013). Table 3 highlights selected examples of stimuli-responsive polymeric micelles from the recent literature.

\section{MULTIFUNCTIONAL POLYMERIC MICELLES DEFINING THE CONCEPT OF MULTIFUNCTIONALITY}

The preceding sections describe various targeting strategies and modifications of polymeric micelles including very basic modifications for longevity which are important for passive targeting of therapeutics solubilized within micelles, surface modification with ligands to allow for selective targeting as well as intracellular delivery of drugs and nucleic acids and finally the modifications which allow micelles to respond to a number of intrinsic and extrinsic stimuli for "triggered" drug release at disease sites. Polymeric micelles, while allowing for the different modifications individually, also offer a platform that allows for integration of multiple components within a single micelle. We can thus engineer micelles to have two or more different modifications that enable them to simultaneously or sequentially perform important therapeutic and diagnostic functions (Torchilin, 2006). Such micelles which can combine a number of distinct functions or properties within a single carrier, with each individual component functioning seamlessly and in perfect coordination with the other components, give rise to the so-called "multifunctional" micelles. In addition to the various modifications just mentioned, contrast or reporter moieties can be incorporated within micelles which allow real-time imaging of these micelles and their accumulation within cells (Torchilin, 2006). Thus, an ideal multifunctional micelle may simultaneously deliver drugs/biologics, circulate in the body for extended periods, allow for passive or active targeting-mediated accumulation, respond to various stimuli to release incorporated cargoes, and may also provide 
Table 3 | Some examples of stimuli-responsive polymeric micelles.

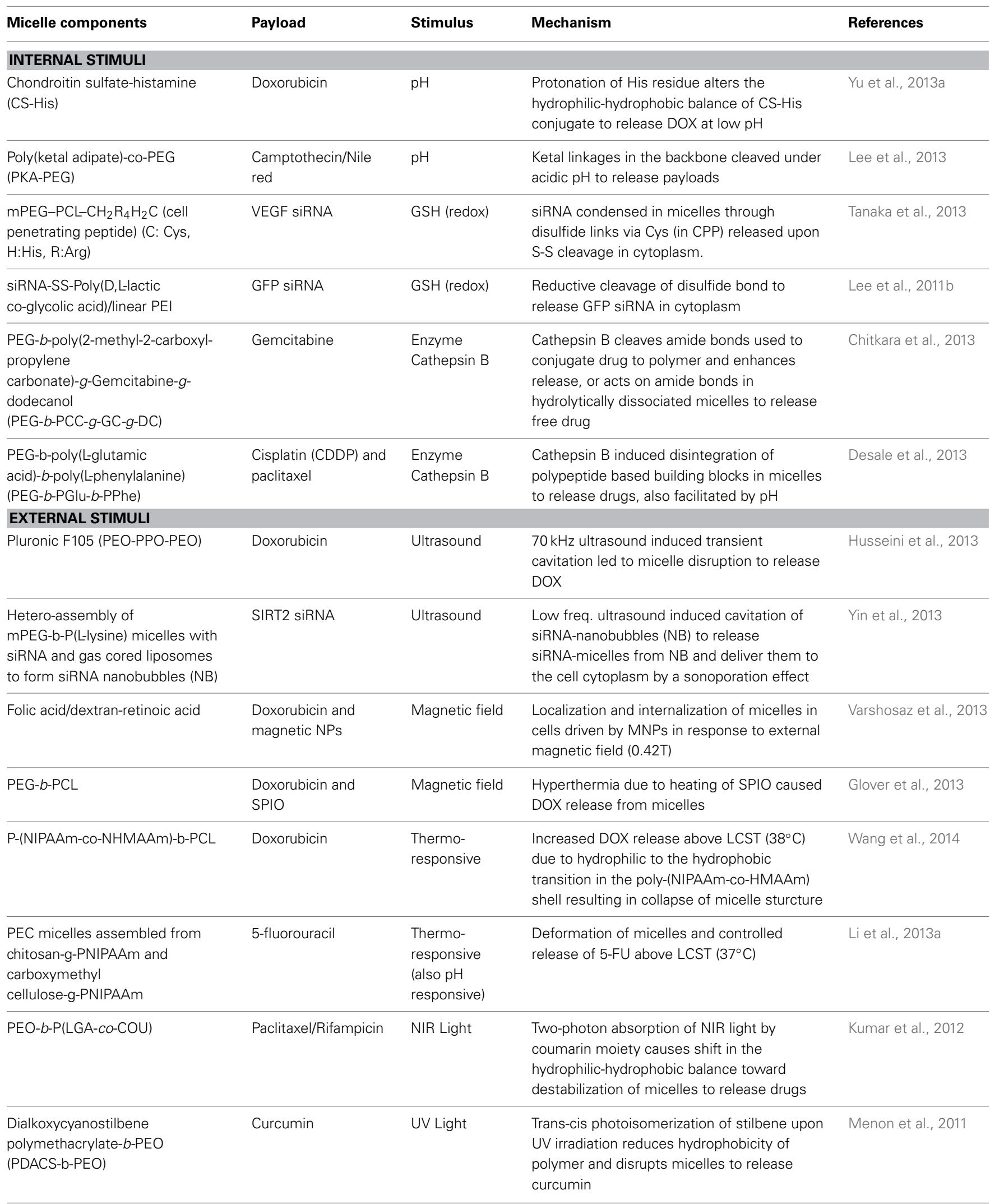

SPIO, Superparamagnetic iron oxide; P-(NIPAAm-co-NHMAAm)-b-PCL, P-(N,N-isopropylacrylamide-co-N-hydroxymethylacrylamide)-b-caprolactone; $\quad P E C$, Polyelectrolyte complex micelles; 6-bromo-7-hydroxycoumarin-4-ylmethyl (COU); NP, Nanoparticles. 
diagnostic and therapeutic monitoring abilities (Figure 4). The key to developing such multifunctional micelles is to ensure that each of the components function in a coordinated manner so that the combined contribution of each adds up to something better than the individual components themselves. It is analogous to an orchestra, where each instrument must be played in perfect harmony to create a beautiful symphony. Cancer is a complex disease characterized by molecular and phenotypic heterogeneity within and between tumor types which makes chemotherapy very challenging. Although, molecularly targeted therapies have been developed, a selection of tumor cells may still escape the targeted pathway and lead to adaptive resistance, causing the failure of therapy (Blanco et al., 2009). It follows from the discussion above that using a multi-faceted approach for targeting cancer seems imperative. While it may be difficult to incorporate all the features of the "ideal" multifunctional polymeric micelle, a combination of two or more of the desirable features is feasible and also necessary for the success of cancer therapy using micellar nanocarriers. A lot of the focus of current research has been in the direction of such multifunctional micelles for their obvious advantages in enhancing the efficacy, maximizing the safety and specificity of existing as well as novel chemotherapy regimens.

\section{MULTIFUNCTIONAL MICELLES FOR DELIVERY OF DRUGS}

Multifunctional polymeric micelles have been investigated extensively in recent times for delivery of drugs as well as nucleic acids. A number of interesting combinations have been explored for drug-loaded multifunctional polymeric micelles, a select few of which are discussed here.

Multifunctional micelles made of block copolymers of PLGAPEG were reported for the combined delivery of DOX and PTX (Duong and Yung, 2013). A cell penetrating moiety (TAT) and a targeting ligand (folate) were used to modify PLGAPEG to achieve an enhanced therapeutic effect for the drug combination vs. the single drugs. The authors tested single and dual drug-loaded micelles modified either with folate or with both TAT and folate ligands respectively, and found that dual drug-loaded micelles modified with both ligands exhibited a significantly lower $\mathrm{IC}_{50}$ value in $\mathrm{KB}$ cells (mouth epidermal carcinoma) compared to the single drug-loaded micelles. Although a synergistic effect was observed with both methods (co-delivery of two single drug-loaded micelles and dual drug-loaded micelles), the authors hypothesized that the drug ratio would be better maintained in the dual drug-loaded multi-functional formulation in vivo compared to the co-delivery of dual targeted, single drug-loaded micelles (Duong and Yung, 2013). MRI-responsive micelles typically incorporate magnetic nanoparticles within the core, but in a novel approach Li et al. developed hybrid micelles fabricated from Pluronic F127 and a peptide-amphiphile (PA) consisting of segments of a palmitic part, aspartic acid residue and three histidine residues (pal-AAAAHHHD), in which the magnetic nanoparticles were embedded in the shell (Li et al., 2013f). Micelle formation was driven by hydrophobic interactions between hydrophobic segements of Pluronic F127 and PA, with hydrophobic DOX encapsulated within the micelles. The chelating ability of the aspartic acid and histidine residues in the peptide enabled the in situ growth of magnetic nanoparticles within the shell by chemical precipitation of iron oxides. The shell-embedded magnetic nanoparticles significantly improved stability and retarded the release of DOX from the hybrid micelles, due possibly to their crosslinking effect on the shell. The DOXloaded hybrid micelles also served as effective T2 weighted MRI contrast agents both in vitro and in vivo and also had the advantage of a simple, convenient and "green" synthesis under ambient conditions devoid of organic solvents (Li et al., 2013f).

Another novel, targeting-clickable and tumor-cleavable multi-block polyurethane (MPU) nanomicelle formulation was reported for the multifunctional delivery of chemotherapeutics

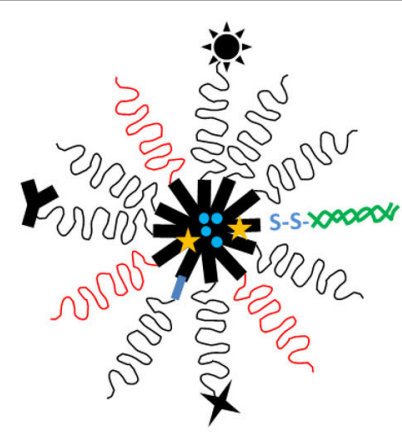

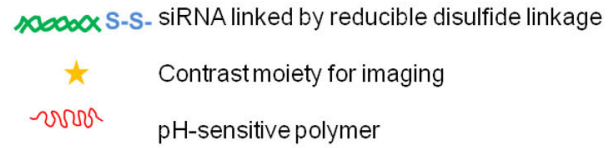

vorr Polymer for long circulation (e.g. PEG)

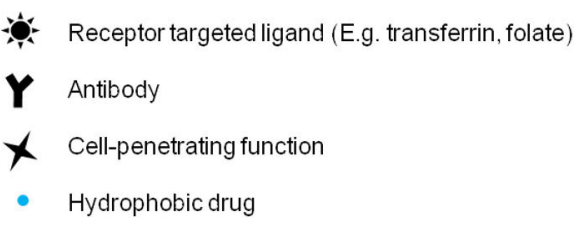

stimuli-sensitive block (intrinsic or extrinsic stimulus)

FIGURE 4 | A hypothetical multifunctional polymeric micelle. Multifunctional polymeric micelles can be designed to incorporate two or more of these different functions. 


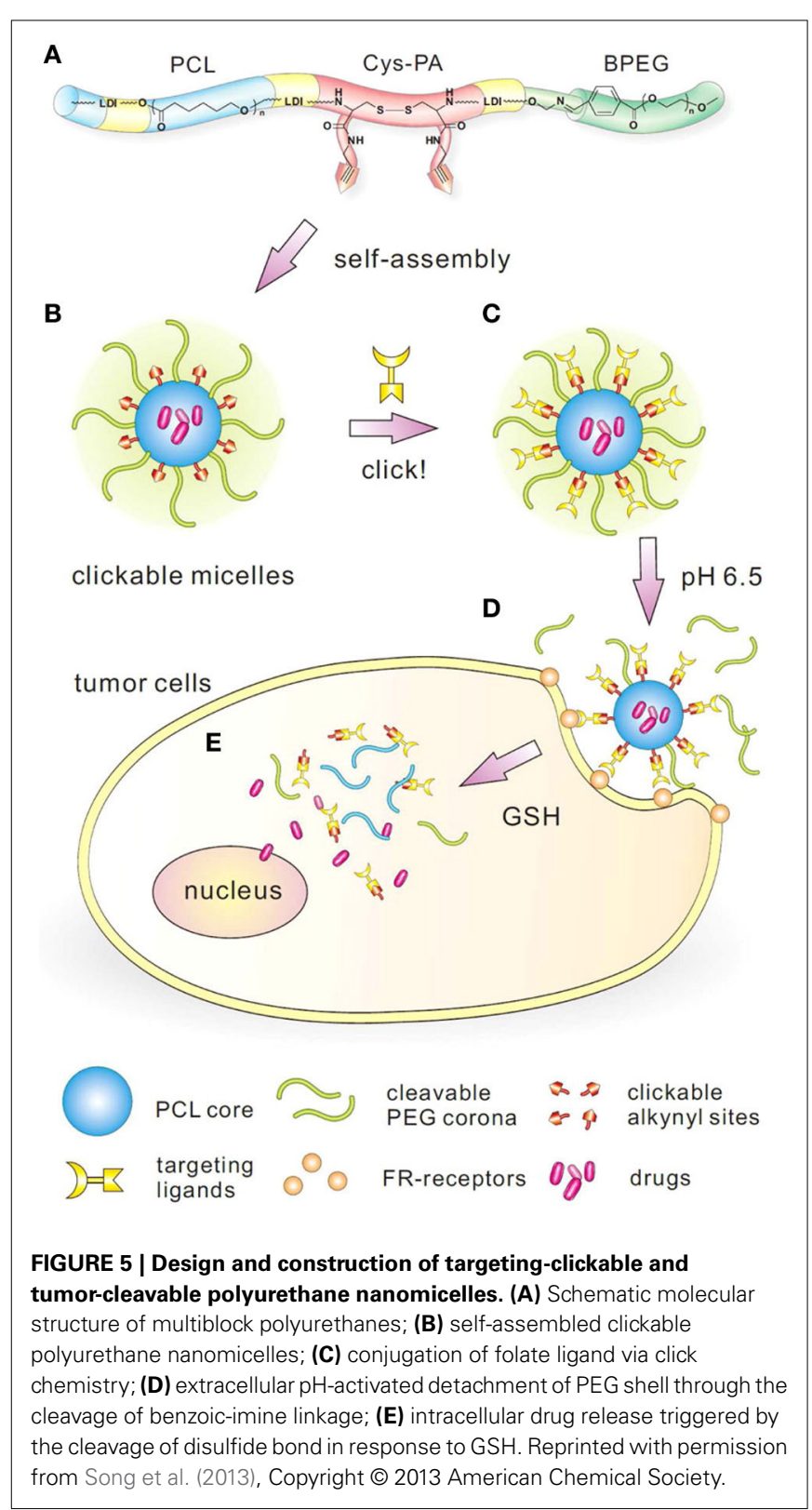

(Song et al., 2013).The polyurethane backbone was composed of poly( $\varepsilon$-caprolactone) (PCL) and L-lysine ethyl ester diisocyanate (LDI). It was extended using a L-cystine-derivatized chain extender bearing redox-sensitive disulfide bonds in the backbone and two clickable alkynyl groups (Cys-PA) in the side-chain for post-functionalization with ligands (Figure 5).

The terminal group was comprised of a detachable mPEG with a $\mathrm{pH}$-sensitive benzoic-imine linkage (BPEG) which could cleave in the slightly acidic conditions $(\mathrm{pH}, 6.5-7.2)$ found in the extracellular tumor environment. The prepared multi-block polyurethanes self-assembled into nanomicelles in an aqueous solution, and DOX was loaded into micelles using the dialysis method. Folic acid (FA) was modified with azide and conjugated to the micelles by the copper catalyzed alkyne-azide cycloaddition (CuAAC) click reaction. The MPU micelles were sensitive to multiple stimuli (intracellular GSH-sensitive drug release and extracellular $\mathrm{pH}$-sensitive PEG detachment) and had a high DOX loading capacity. The folate-targeted micelles showed a higher cellular uptake and increased cytotoxicity over non-targeted micelles in FR positive HeLa cells in vitro (Song et al., 2013). The same group also reported multifunctional MPU micelles loaded with PTX and targeted with C225 monoclonal antibody against the EGFR extracellular domain for intracellular drug delivery. These micelles possessed hydrazone linkages for $\mathrm{pH}$-responsivity, cell penetrating gemini quaternary ammonium (GQA) cationic groups for enhancing cell internalization and a tripeptide containing reactive carboxyl anion groups to provide an active site for conjugation of the targeting antibodies (Ding et al., 2013).

Zhu et al. developed a unique tumor-targeted micellar drugdelivery platform combining several key strategies in a collaborative manner to simultaneously counter many of the key challenges faced by chemotherapeutics (Zhu et al., 2013). The authors synthesized a self-assembling drug-polymer conjugate/prodrug, PEG2000-peptide-PTX with an MMP cleavable linker GPLGIAGQ between PEG and PTX. This functioned as a tumor environment-sensitive water-soluble PTX prodrug and an MMP2-sensitive building block for a PTX nanopreparation. MMP-2 sensitive micelles were composed of the PTX prodrug PEG2000-peptide-PTX (50 mol\%) and two other polymers, TATp-PEG1000-PE (10 mol\%) (cell-penetration enhancer) and PEG1000-PE (40 mol\%) (nanocarrier building block) following their self-assembly in an aqueous environment as shown in Figure 6. In the MMP-2 sensitive nanopreparation (TATpPEG1000-PE/PEG2000-peptide-PTX), PTX was loaded in the core surrounded by the hydrophilic PEG shell. After accumulation of micelles within tumors by the EPR effect, the peptide linker was cleaved by the upregulated extracellular MMP2, to allow liberation of the active PTX and exposure of the hidden TATp (attached to a shorter PEG chain) for cell internalization. The MMP2-sensitive, TATp-modified, micellar formulation showed a high PTX loading $(15 \% \mathrm{w} / \mathrm{w})$ with low risk of premature drug release/leakage, had a superior cell internalization and hence cytotoxicity in vitro, as well as greater tumor targeting and anti-tumor efficacy in vivo compared to the non-MMP2 sensitive formulation, free PTX or conventional micelles (PEG2000$\mathrm{PE} / \mathrm{PTX}$ ). This formulation thus exhibited its potential for cancer cell-selective intracellular delivery for enhanced cancer therapy by combining multiple delivery strategies including self-assembly, PEGylation, accumulation by EPR effect, stimulus sensitivity, cellpenetrating moiety and the concept of a prodrug (Zhu et al., 2013).

In addition to micelles made from common diblock copolymers, asymmetric tri-block copolymers have also been reported. Bastakoti et al. developed multifunctional core-shell-corona polymeric micelles using a special type of asymmetric tri-block copolymer poly(styrene-acrylic acid-ethylene glycol) (PS-PAAPEG) (Bastakoti et al., 2013). The self assembly of PS-PAA-PEG in aqueous solutions produces micelles with a PS core, an anionic PAA shell and a neutral and hydrophilic PEG corona. Nile red (NR), a phenoxazine dye was loaded in the PS core using the dialysis method. Cisplatin was incorporated in the $\mathrm{pH}$-sensitive PAA shell to allow for faster release at mildly acidic $\mathrm{pH}(5.0)$ 


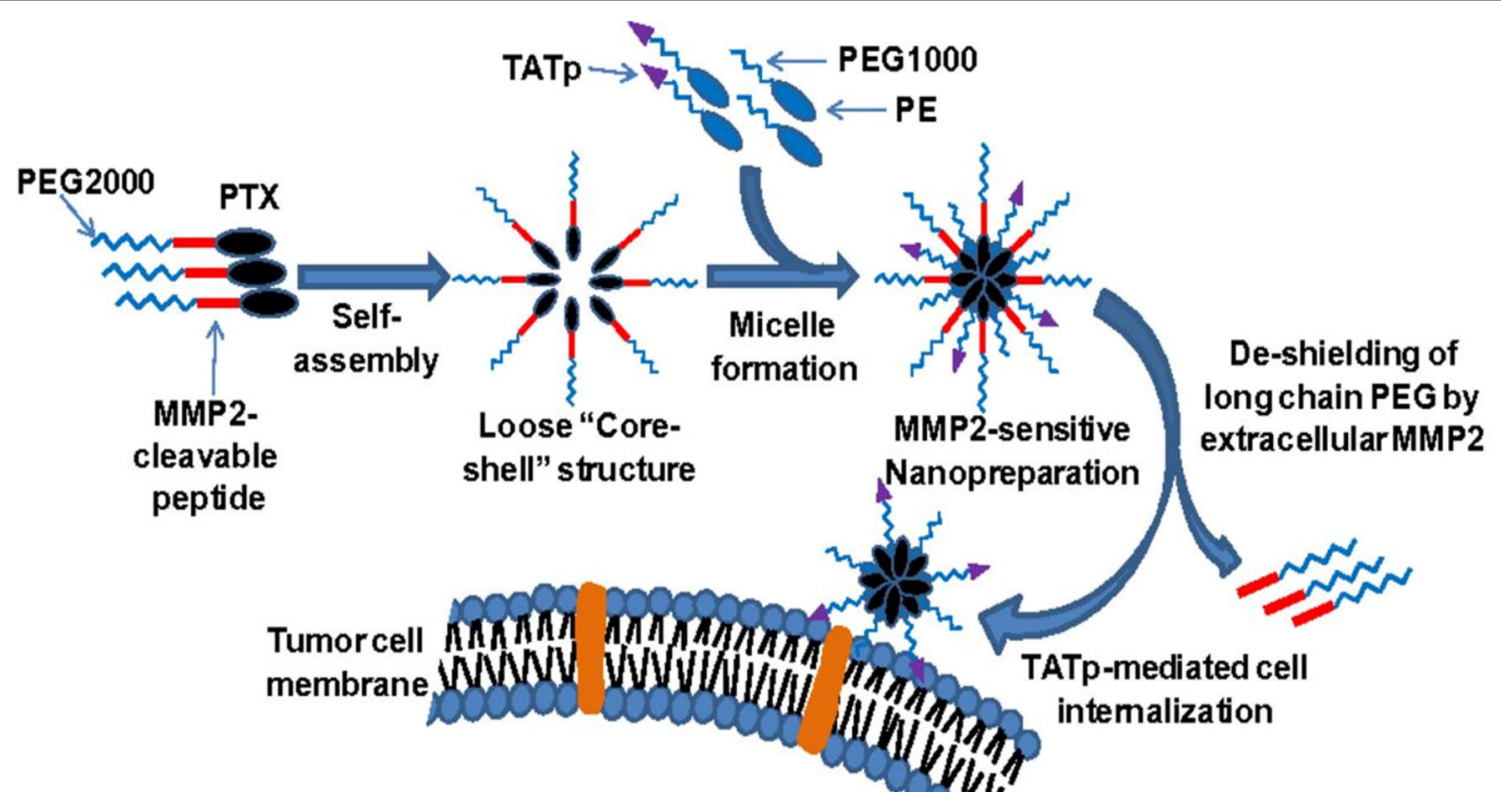

FIGURE 6 | MMP-2 sensitive nanopreparations. Modified from Zhu et al. (2013), Copyright @ 2013 PNAS.

compared to the normal physiological $\mathrm{pH}$. The interaction of cisplatin with micelles was enhanced due to the abundant carboxylic groups on the PAA shell. Calcium phosphate $(\mathrm{CaP})$ was selectively mineralized on the PAA shell, which enhanced the fluorescence intensity of NR, provided improved diagnostic efficacy and detection sensitivity and also acted as a diffusion barrier for controlled release of cisplatin. The PEG shell provided steric protection and prevented micelles from aggregating. The NR containing polymeric micelles were taken up by Hep G2 cells and localized in the nuclei and cytoplasm. They were non-toxic and had excellent biocompatibility, exhibiting $90 \%$ viability at polymer concentrations upto $500 \mu \mathrm{g} / \mathrm{mL}$. Cisplatin-loaded micelles exhibited a dose-dependent cytotoxic effect on the Hep G2 cells (Bastakoti et al., 2013).

Additional examples of multifunctional drug-loaded micelles are outlined in Table 4.

\section{CHALLENGES FOR THE DELIVERY OF SIRNA AND THE ROLE OF POLYMERIC MICELLES}

Since the discovery of RNAi, there has been an increased interest in developing siRNA based therapies to achieve sequence-specific post-transcriptional silencing of aberrant genes in diseases such as cancer (Fire et al., 1998; Elbashir et al., 2001). RNAi is an endogenous pathway which is utilized by all eukaryotic cells to silence genes post-transcriptionally, and can be triggered by double stranded RNAs (dsRNA) like endogenous microRNA (miRNA), short hairpin RNA (shRNA) and synthetic siRNA (Wang et al., 2010b). The detailed mechanism of the RNAi pathway has been reviewed elsewhere (Hannon, 2002; Rana, 2007; Sashital and Doudna, 2010). Briefly, the dsRNA is processed by the Dicer enzyme into small fragments which are 21-23 nucleotide (nt) base pairs in length (Meister and Tuschl, 2004). The fragments, which possess a sense (passenger) strand and an antisense (guide) strand with respect to the target mRNA, are loaded into the RNA-induced silencing complex (RISC). Here the strands are separated, and the sense strand is cleaved and discarded. The activated RISC-guide strand complex is then directed to the complementary region of the target mRNA to cause it to degrade and prevent its translation (Martinez et al., 2002). Synthetic siRNAs can be introduced into the cell directly and avoid processing by Dicer (Whitehead et al., 2009).

To access and activate the RNAi machinery, the siRNA must be delivered to the cytoplasm of the cell. However, this "delivery of siRNA" poses one of the most formidable challenges to realizing the potential and utility of siRNA therapeutics. Whereas localized targets are accessed directly, the main hurdle is encountered when siRNA is delivered to tissues which are accessed only through systemic administration of agents via the blood (Whitehead et al., 2009). A number of barriers prevent the successful systemic delivery of siRNA. After intravenous administration, naked siRNA exhibits low in vivo stability due to quick degradation by nucleases. It has a short half-life due to rapid clearance by the kidneys and uptake by the MPS. The hydrophilic nature and negative charge of siRNAs prevent them from crossing the plasma membrane easily, despite their relatively small size (about $13 \mathrm{kDa}$ ) (Liu et al., 2013; Navarro et al., 2013). Other challenges with siRNA include the potential to generate off-target effects due to silencing of genes that have partial homology with the siRNA and engagement of the immune system components to cause immune stimulation (Bumcrot et al., 2006). Moreover, because siRNAs also share the RNAi pathway with endogenous miRNAs, they may compete for the RNAi machinery, saturate it and inhibit normal gene regulation by miRNAs (Kanasty et al., 2012). A number of approaches have been suggested to overcome some of the aforementioned challenges. Chemical modification of the sugars, phosphate linkage or bases of siRNA can increase its 
Table 4 | Some examples of multifunctional drug-loaded micelles.

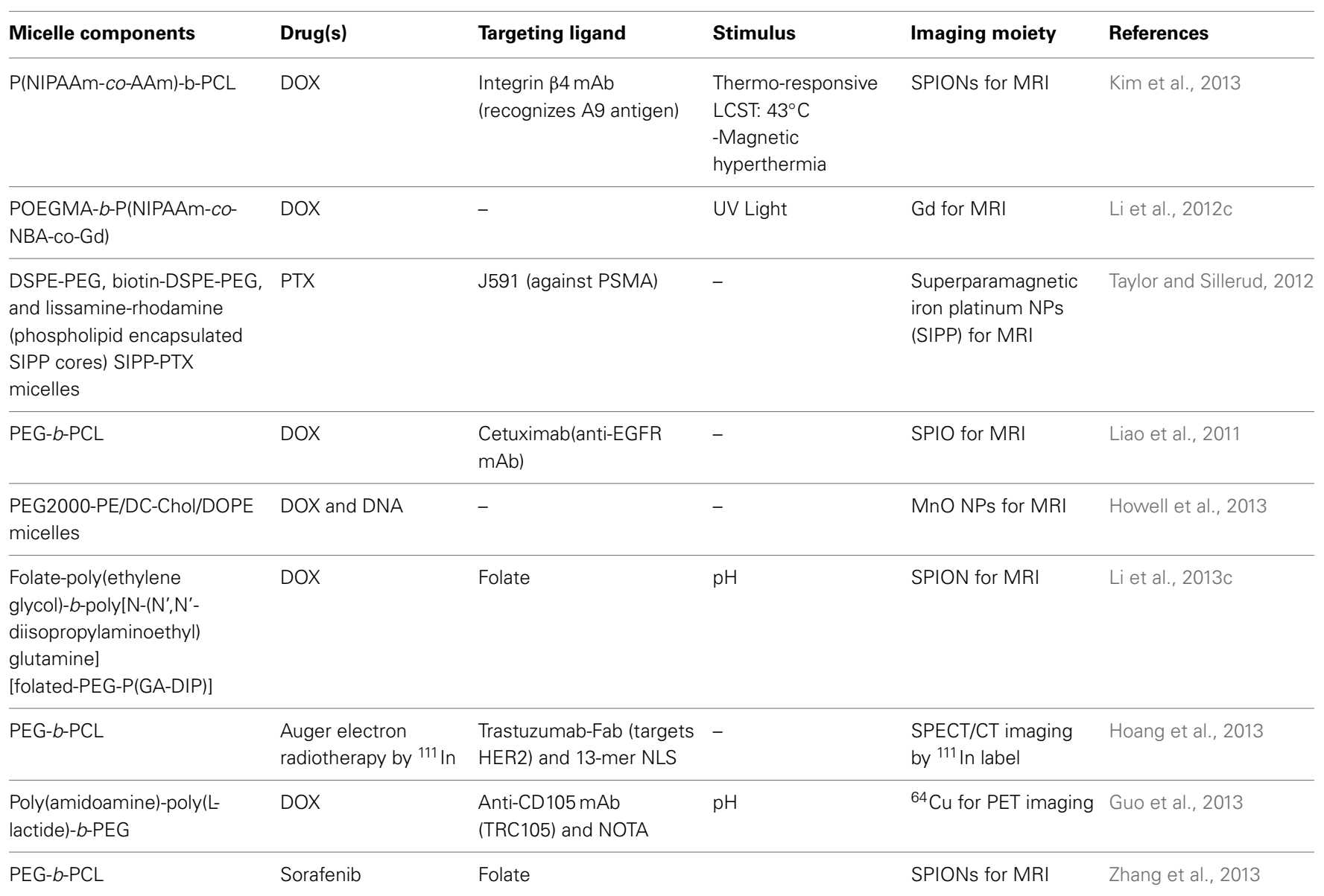

POEGMA-b-P(NIPAAm-co-NBA-co-Gd), Poly(oligo(ethylene glycol) monomethyl ether methacrylate-b-Poly(N-isopropylacrylamide)-co-o-nitrobenzyl acrylate-co-Gd; DOX, Doxorubicin; PTX, Paclitaxel; CREKA, Cys-Arg-Glu-Lys-Ala; NLS, Nuclear localization signal (13 mer peptide CGYGPKKKRKVGG); NOTA, 1,4,7-triazacyclononane$\mathrm{N}, \mathrm{N}, \mathrm{N}$-triacetic acid (macrocyclic chelator for ${ }^{64} \mathrm{Cu}$ ).

stability and also reduce the immune stimulation. Modifications of the $2^{\prime}$ sugar position $\left[2^{\prime}\right.$-fluoro $\left(2^{\prime}-\mathrm{F}\right), 2^{\prime}$-O-methyl $\left(2^{\prime}-\mathrm{O}-\mathrm{Me}\right)$ and $2^{\prime}$-O-methoxyethyl $\left(2^{\prime}\right.$-MOE) $]$, locked nucleic acids (LNA) and unlocked nucleic acids (UNA) increase the endonuclease resistance and reduce immunostimulatory activity, whereas introduction of a phosphorothioate (PS) linkage at the $3^{\prime}$ end in the backbone is known to increase stability and resist against exonucleases (Bumcrot et al., 2006). Base modifications are less common than those of sugar or phosphate linkages, but have been employed. The use of 2-thiouracil or pseudouracil can increase the binding specificity and potency and 5-methylation of pyrimidines (using $\mathrm{T}$ and $5-\mathrm{Me}-\mathrm{C}$ instead of $\mathrm{U}$ and $\mathrm{C}$ ) is also common (Watts et al., 2008). The off-target effects of siRNA and its saturation of the RNAi machinery can be avoided by optimizing the siRNA sequence and structure, and limiting doses of exogenous RNA respectively (Kanasty et al., 2012; Navarro et al., 2013).

The issues of instability in circulation, rapid clearance and short half-life of naked siRNA can be addressed by chemically modifying siRNA or by employing nanocarriers which can protect it from degradation and immune recognition as well as modify its pharmacokinetics favorably in vivo (Pecot et al., 2011;
Kanasty et al., 2012). The negative charge of siRNA can be masked using cationic carriers which complex the siRNA electrostatically. The positive charge of these carriers also helps in cellular internalization (Musacchio and Torchilin, 2013).

A nanocarrier must possess certain features to be successful as a carrier for systemic siRNA delivery. Ideally, a nanocarrier should: (a) be non-toxic and non-immunogenic, (b) condense siRNA effectively, (c) be stable in the presence of nucleases, (d) protect the siRNA from immune recognition, (e) be large enough to avoid clearance by kidneys, yet small enough to avoid phagocytosis by MPS, (f) avoid non-specific interactions with serum proteins and non-target cells, (g) reach target tissues from the blood and eventually the intracellular compartment, and (h) release the entrapped siRNA efficiently in the cytoplasm to access the siRNA machinery (Daka and Peer, 2012; Kanasty et al., 2013). Polymeric micelles have been used successfully as drug delivery vehicles for the past few decades, which has prompted their use as vehicles for siRNA. Moreover, by engineering micelles with suitable modifications discussed in the previous sections, they may likely meet most criteria for an "ideal" nanocarrier for siRNA. 
So far, two main strategies have been used to design polymeric micelles for siRNA delivery. The first involves direct conjugation of hydrophilic (PEG) or hydrophobic (lipid) moieties to siRNA via degradable (e.g., disulfide) or non-degradable linkages, followed by their condensation with polycationic ions to form micellar structures called polyion complex micelles (PICs) or polyelectrolyte complex micelles (PECs). In PIC micelles, the polyion segments are usually made of poly(amino acids) like poly(aspartic acid) or poly(L-lysine) or PEI (Oishi et al., 2005; Kim et al., 2008; Suma et al., 2012). In the second strategy, siRNA is complexed with an amphiphilic block copolymer containing polycation (or lipid) segment followed by micellization of the block copolymer-siRNA complex (Falamarzian et al., 2012; Navarro et al., 2013). Nanoparticles including polymeric micelles enter cells by endocytosis (Decuzzi and Ferrari, 2008). One of the major intracellular barriers for siRNA delivery is that of endosomal escape following its delivery by various carriers. Following endocytosis, the siRNA-loaded carriers in membranebound endocytic vesicles fuse with early endosomes to become increasingly acidic as they mature into late endosomes $(\mathrm{pH} 5-$ 6). Finally the endosomal contents are delivered to the lysosome, where the $\mathrm{pH}$ drops further $(\mathrm{pH} \sim 4.5)$, and where hydrolysis of proteins and nucleic acids take place (Dominska and Dykxhoorn, 2010; Singh et al., 2011). To avoid lysosomal degradation, it is essential for the siRNA to escape the endosome, be released into the cytosol and interact with the RNAi machinery (Dominska and Dykxhoorn, 2010). To overcome this "endosomal escape barrier," polymeric micelles can be designed to incorporate cationic polymers such as PEI which act as "proton sponges" to disrupt the endosomes and release siRNA in the cytosol. Alternatively, $\mathrm{pH}$ responsive polymers can be used to construct polymer micelles, so that they disrupt and release the siRNA at the endosomal $\mathrm{pH}$. Finally fusogenic lipids, cell penetrating peptides, other polymers with high buffering capacity and photosensitizers (upon light activation they induce endosomal disruption via singlet oxygen production) can be used to engineer polymeric micelles to overcome the issue of endosomal escape (Dominska and Dykxhoorn, 2010). In the sections that follow, we discuss some examples of multifunctional micelles from the recent literature which have been used to deliver either siRNA alone or siRNA in combination with drugs.

\section{MULTIFUNCTIONAL MICELLES FOR DELIVERY OF siRNA}

Many interesting micelle-forming amphiphilic block copolymers have been developed for siRNA delivery over the past few years. These basic platforms are being modified continuously to achieve maximum benefit from them, by introducing targeting ligands or incorporating environmentally-sensitive blocks or links within them. For all siRNA delivery platforms including micelles, a major focus is on preventing siRNA degradation from the time it is introduced in the systemic circulation, until it reaches the RNAi machinery in the cytoplasm, after navigating the endocytic pathway for intracellular trafficking and its subsequent endosomal escape.

Christie et al. reported the development of multifunctional micelles for siRNA delivery formed from the stable assembly of siRNA with block copolymers possessing three main features: a siRNA binding segment containing thiols, a hydrophilic non-binding segment and a cell-surface binding peptide (Christie et al., 2012). The block copolymer used was PEG-b-poly $\left(\mathrm{L}^{-}\right.$ lysine) (PEG-b-PLL) containing lysine amines modified with 2-iminothiolane (2IT). Building on their previous work where the RNAi activity of the micelles formed using this copolymer was found to be low (Matsumoto et al., 2008), the authors further modified the block copolymer with cyclo-Arg-Gly-Asp (cRGD) peptide at the PEG terminus to enhance tumor accumulation, cell uptake and sub-cellular distribution. The 2IT modification of the lysine amines introduced amidines and free thiols into the lysine segment of the block copolymer, which increased the stability of micelles through disulfide cross-linking in the core. It also imparted micelles with a site-specific siRNA release function in response to the highly reducing environment within cells. The $2 \mathrm{IT}$ modification also had a micellestabilizing effect due to the formation of cyclic-N-substituted 2IT ring structures in the lysine side chains. Electrostatic interactions between oppositely charged macromolecules resulted in charge neutralization and self-assembly to form micelles, with siRNA incorporated into the micelle core and PEG forming the shell. The cRGD-targeted micelles improved siRNA delivery both in vitro and in vivo. Micelles incorporating siRNAs against VEGF (to target tumor mass) and those incorporating siRNA against vascular endothelial growth factor receptor 2 (VEGFR2) (to target blood vessel endothelial cells) were prepared. The siRNA-loaded, cRGD-modified micelles enhanced the gene silencing ability, improved cell uptake, and had better sub-cellular distribution in vitro. They also improved accumulation in the tumor mass and tumor-associated blood vessels following i.v. injection in mice. They also effectively inhibited growth of subcutaneous HeLa-Luc tumors and silenced genes in the tumor mass following treatment with antiangiogenic siRNAs. No tumor growth reduction was observed with naked siRNA, micelles lacking the cRGD peptide, or those without 2IT-modified lysines, which was consistent with in vitro results (Christie et al., 2012). TAT, another cell-penetrating peptide was conjugated via a disulfide bond to an amphiphilic block copolymer mPEG-PCL and evaluated for siRNA delivery both in vitro and in vivo (Kanazawa et al., 2012). The MPEG-PCLSS-TAT/siRNA micelles showed a significantly higher intracellular uptake of 6-carboxyfluorscein-aminohexyl (FAM)-siRNA than naked FAM-siRNA and an uptake equivalent to the positive control LipoTrust at a nitrogen to phosphate $(\mathrm{N} / \mathrm{P})$ ratio of 30 . The micelles without siRNA (MPEG-PCL-SS-TAT) did not induce substantial cytotoxicity in S-180 sarcoma cells at any of the reported N/P ratios. The MPEG-PCL-SS-TAT/anti-VEGF siRNA micelle complexes were evaluated in vivo in S-180 sarcoma tumorbearing mice. Relative to control mice and to groups injected with naked VEGF siRNA or control siRNA bearing micelles, the tumor volumes were significantly suppressed for the MPEG-PCL-SSTAT/siVEGF group, which correlated with the reduction in VEGF secretion from these tumors. The suppressed VEGF secretion was attributed to improved siRNA release in the cytosol after cleavage of the S-S bond by intracellular GSH, which enables release of TAT and the dissociation of siRNA from micelles (Kanazawa et al., 2012). 
Significant levels of resident macrophages have been observed in many cancers, which have been correlated with poor prognoses. Tumor associated macrophages thus represent an interesting target for cancer therapy (Lewis and Pollard, 2006). However, the delivery and cytoplasmic release of siRNA in macrophages is a challenging task, due to their high degradative potential. Yu et al. reported $\mathrm{pH}$-responsive polymeric micelles which were mannosylated using "click" chemistry to allow CD206 (mannose receptor)-targeted siRNA delivery to tumor associated macrophages which show an up-regulation of these receptors (Yu et al., 2013b). The mannosylated micelles had been incorporated with various functions in their polymer blocks and were synthesized in three stages: (I) Sequential reverse additionfragmentation chain transfer (RAFT) polymerization and purification was first used to synthesize the polymeric components, (II) Alkyne functionalized mannose was synthesized separately, and (III) The polymers from stage (I) were formed into micelles and reacted with alkyne functionalized mannose from stage (II) using alkyne-azide click chemistry which immobilizes mannose on the micelle corona. The micelle blocks consisted of a $\mathrm{pH}$-responsive, core-forming terpolymer capable of disrupting endosomes at low $\mathrm{pH}$ (butyl methacrylate-co-2-propyl acrylic acid-co-2-dimethylaminoethyl methacrylate) (BMA-co-PAA-coDMAEMA), a cationic block for condensing siRNA (DMAEMA) and an azide-presenting corona-forming block for the attachment of alkyne-functionalized mannose (2-azidoethyl methacrylate (AzEMA) (Figure 7).

The resulting triblock copolymers poly(BMA-co-PAA-coDMAEMA)- $b$-poly(DMAEMA)- $b$-poly(AzEMA) self-assembled into micelles in aqueous media at $\mathrm{pH}$ 7.4. The mannosylated micelle nanoparticles (ManNPs) had a four-fold improved siRNA delivery into macrophages compared with non-targeted carriers and achieved $87 \pm 10 \%$ knockdown of a model gene in primary macrophages following a $24 \mathrm{~h}$ treatment. They preferentially delivered siRNA into immortalized human macrophages (13-fold higher) relative to model breast cancer cell lines. The ManNPs as well as diblock copolymers without the targeting agent were both capable of escaping the endosomal compartment in a $\mathrm{pH}$-dependent manner as confirmed by the red blood cell (RBC) hemolysis assay, a function conferred by the coreforming, $\mathrm{pH}$-responsive, endosomolytic terpolymer block (Yu et al., 2013b). The same pH-responsive terpolymer block was previously reported by Palanca-Wessels et al. in another multifunctional micellar system for CD22 receptor-targeted delivery of siRNA to lymphoma cells. The CD22-targeted polymeric micelles were effective at a low dose of $15 \mathrm{nmol} / \mathrm{l}$ siRNA and produced a $70 \%$ reduction in glyceraldehyde-3-dehydrogenase (GAPD) gene expression in DoHH2 lymphoma cells (Palanca-Wessels et al.,

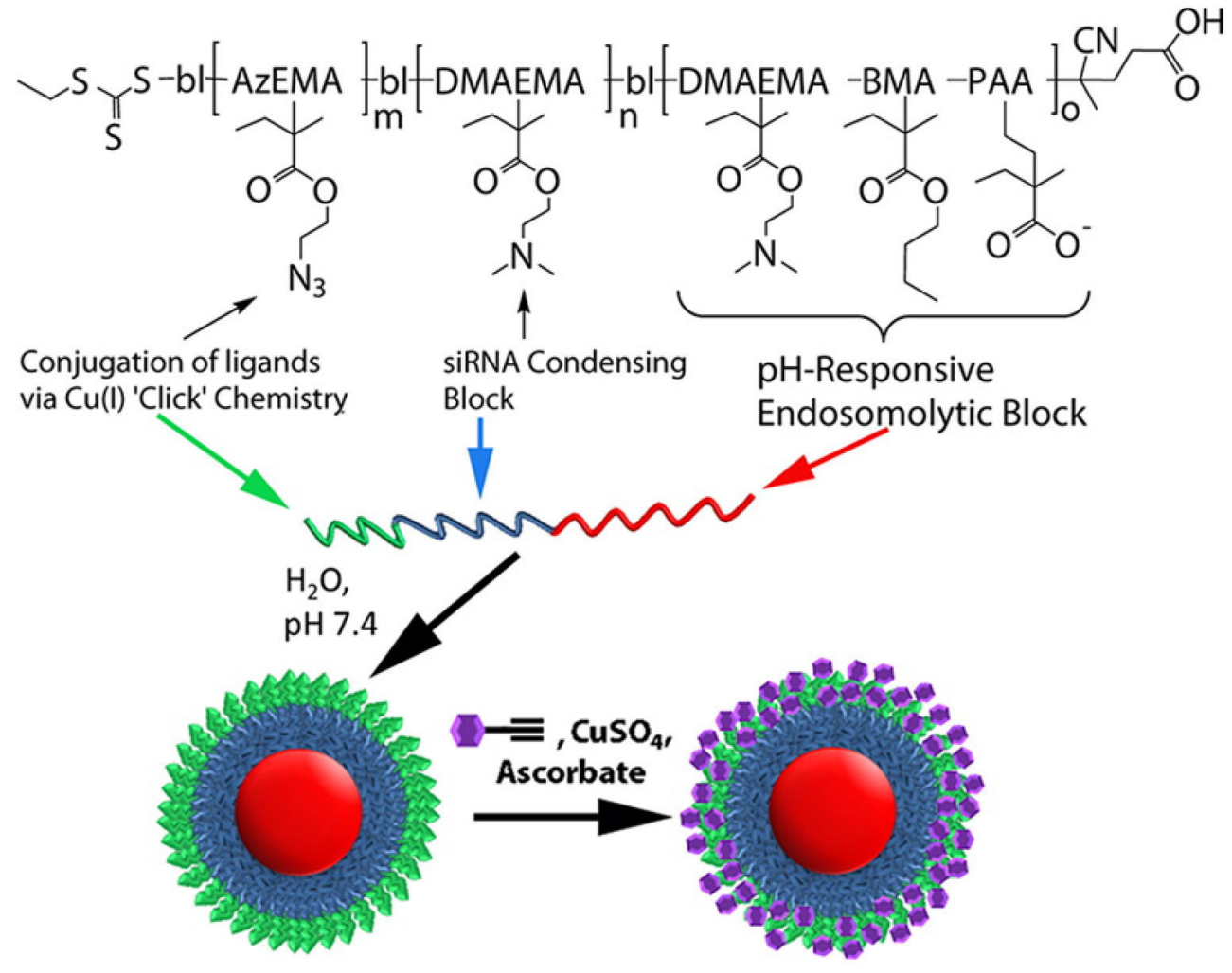

FIGURE 7 | Smart polymeric nanoparticles for mannose receptor-targed cytosolic delivery of siRNA. Schematic representation of the triblock copolymers and formulation into multifunctional nanoscale siRNA delivery vehicles. The blocks include a $\mathrm{pH}$-responsive block that is capable of disrupting endosomes at low pH (red), a cationic block for condensation of nucleic acids (blue), and an azide-displaying block (green) for conjugation of targeting motifs (purple) via click chemistry. Reprinted with permission from Yu et al. (2013b), Copyright @ 2013 American Chemical Society. 
2011). Leroux and co-workers also reported $\mathrm{pH}$-responsive, coreshell type PIC micelles (PICMs) decorated with an antibody fragment directed against the transferrin receptor (anti-CD71) for delivery of siRNA (Felber et al., 2011). The micelles were prepared by complexing poly(ethylene glycol)- $b$-poly(propyl methacrylateco-methacrylic acid) (PEG- $b$-P(PrMA-co-MAA) with different polyamidoamine (PAMAM) dendrimers and nucleic acids to form the PICMs. Under mildly acidic conditions found within the endosomal compartment, the PICMs lose their shell to release the PAMAM/nucleic acid core due to protonation of MAA units. The micelles were stable in serum and protected siRNA from degradation. Cell uptake studies with PC-3 (prostate cancer) cells using flow cytometry revealed a significantly higher uptake for the anti-CD71 Fab'-PICMs when compared to native PICMs and non-specific antibody-bearing micelles. The targeted, siRNA-loaded PICMs down-regulated the expression of the antiapoptotic oncoprotein $\mathrm{Bcl}-2$ in vitro, when using either the unmodified or $2^{\prime}$-modified ( $2^{\prime}$ F-RNA and $2^{\prime}$ F-ANA) sequences. The chemically modified siRNA however required a five-fold lower concentration (10 vs. $50 \mathrm{nM}$ to achieve the same silencing as the unmodified siRNA (Felber et al., 2011).

Additional examples for multifunctional siRNA-loaded micelles are given in Table 5.

\section{MULTIFUNCTIONAL MICELLES FOR THE COMBINED DELIVERY OF DRUGS AND siRNA}

siRNA therapy using polymeric micelles has shown considerable promise and is being investigated widely. However, tumors are highly prone to genetic mutations, which may hinder the effectiveness of siRNA as a single agent in the treatment of malignancies (Liu et al., 2013). Moreover, conventional anti-cancer agents also suffer from limitations like off-target effects and multi-drug resistance (MDR), both of which hamper cancer therapy significantly. Efforts to develop molecules which inhibit the function of the drug transporter proteins like P-glycoprotein (Pgp) (encoded by the MDR1 gene) to sensitize tumor cells to anti-cancer agents have met with limited clinical success so far, due to the nonspecific nature of these inhibitors (Shukla et al., 2008). In such cases, employing RNAi to down-regulate the expression of MDR genes to specifically inhibit Pgp expression rather than merely its function, followed by conventional chemotherapy could reap greater benefits for cancer therapy (Wu et al., 2003). A number of studies have reported that pre-treatment of cancer cells with siRNAs followed by conventional anticancer drugs can sensitize the cells significantly toward the drug and make therapy more effective (Spankuch et al., 2007; Macdiarmid et al., 2009; Zhang et al., 2011a; Salzano et al., 2014). However, to gain the maximum effect from both siRNA and drug in vivo, they must be delivered simultaneously to the same tumor cell following systemic administration and, ideally, distribute within cells at an optimized ratio for maximal cooperation (Sun et al., 2011b). In this section, we discuss some examples of multifunctional polymeric micelles which incorporate siRNA as well as drug within the same nanocarrier.

Multifunctional micelles composed of PEO-b-PCL block copolymers were reported with functional modifications on both the blocks (Xiong and Lavasanifar, 2011). These micelles could co-deliver siRNA and DOX, enable passive and active targeting, provide for cell membrane translocation and provide a $\mathrm{pH}$-triggered drug release in the endosomes. The PCL core of the micelles incorporated short polyamines (spermine $(\mathrm{SP})$ ) to complex MDR1 siRNA, conjugated DOX chemically via a $\mathrm{pH}-$ sensitive hydrazone linkage, and they could also conjugate fluorescent imaging probes to track micelles in vitro and in vivo. To the virus-like shell of these micelles, two ligands were attached: an active targeting ligand, RGD4C specific for integrin $(\alpha v \beta 3)$ receptors and a cell penetrating TAT-peptide to facilitate the intracellular uptake (Figure 8).

Table 5 | Examples of multifunctional siRNA-loaded micelles.

\begin{tabular}{|c|c|c|c|c|}
\hline Micelle forming components & siRNA & Targeting ligand & Stimulus & References \\
\hline PEO- $b-\mathrm{PCL}$ & MDR1 siRNA & RGD4C (targets $\alpha_{v} \beta_{3}$ )/TAT (CPP) & - & Xiong et al., 2010 \\
\hline PEG-b-poly(_-lysine)-g-(ss-IPEI) & XIAP (anti-apoptotic) siRNA & Herceptin (targets Her2/neu) & Redox (disulfide bonds) & Li et al., 2014 \\
\hline $\begin{array}{l}\text { PEG- } b-\mathrm{P}(\mathrm{PrMA}-\mathrm{co}-\mathrm{MAA}) \text { shell } \\
\text { and PAMAM core PIC micelles }\end{array}$ & Bcl-2 siRNA & $\begin{array}{l}\text { Anti-CD71 Fab'(targets } \\
\text { transferrin receptors }\end{array}$ & $\mathrm{pH}$ & Elsabahy et al., 2009 \\
\hline 6 arm PEG-Hph1/cl KALA PECs & GFP or VEGF siRNA & Hph1 (CPP) & Redox & Choi et al., 2010 \\
\hline $\begin{array}{l}\text { PDMAEMA- } b \text {-PDPAEMA } \\
\text { (Amphotericin B loaded in } \\
\text { PDPAEMA core) }\end{array}$ & GL3 luciferase siRNA & - & $\begin{array}{l}\text { Dual pH (amphotericin } \\
\text { B caused endosomal } \\
\text { escape via membrane } \\
\text { destabilization) }\end{array}$ & Yu et al., 2011 \\
\hline $\begin{array}{l}\text { mPEG- } b \text {-PCL and PCL- } b \text {-PPEEA } \\
\text { mixed micelles }\end{array}$ & $\begin{array}{l}\text { Apolipoprotein B siRNA } \\
\text { (hepatocyte specific) }\end{array}$ & $\begin{array}{l}\text { N-galactosamine (targets } \\
\text { ASGPr) }\end{array}$ & - & Wang et al., 2013 \\
\hline
\end{tabular}

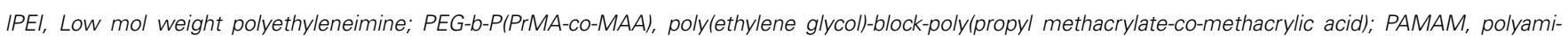
doamine; cl KALA peptide, cross-linked CWEAKLAKALAKALAKHLAKALAKALKAC; Hph1, cell penetrating peptide (YARVRRRGPRR); PDMAEMA-b-PDPAEMA,

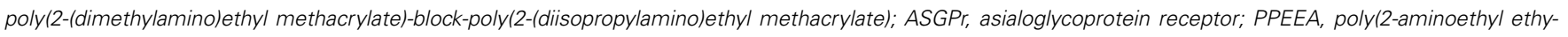
lene phosphate. 


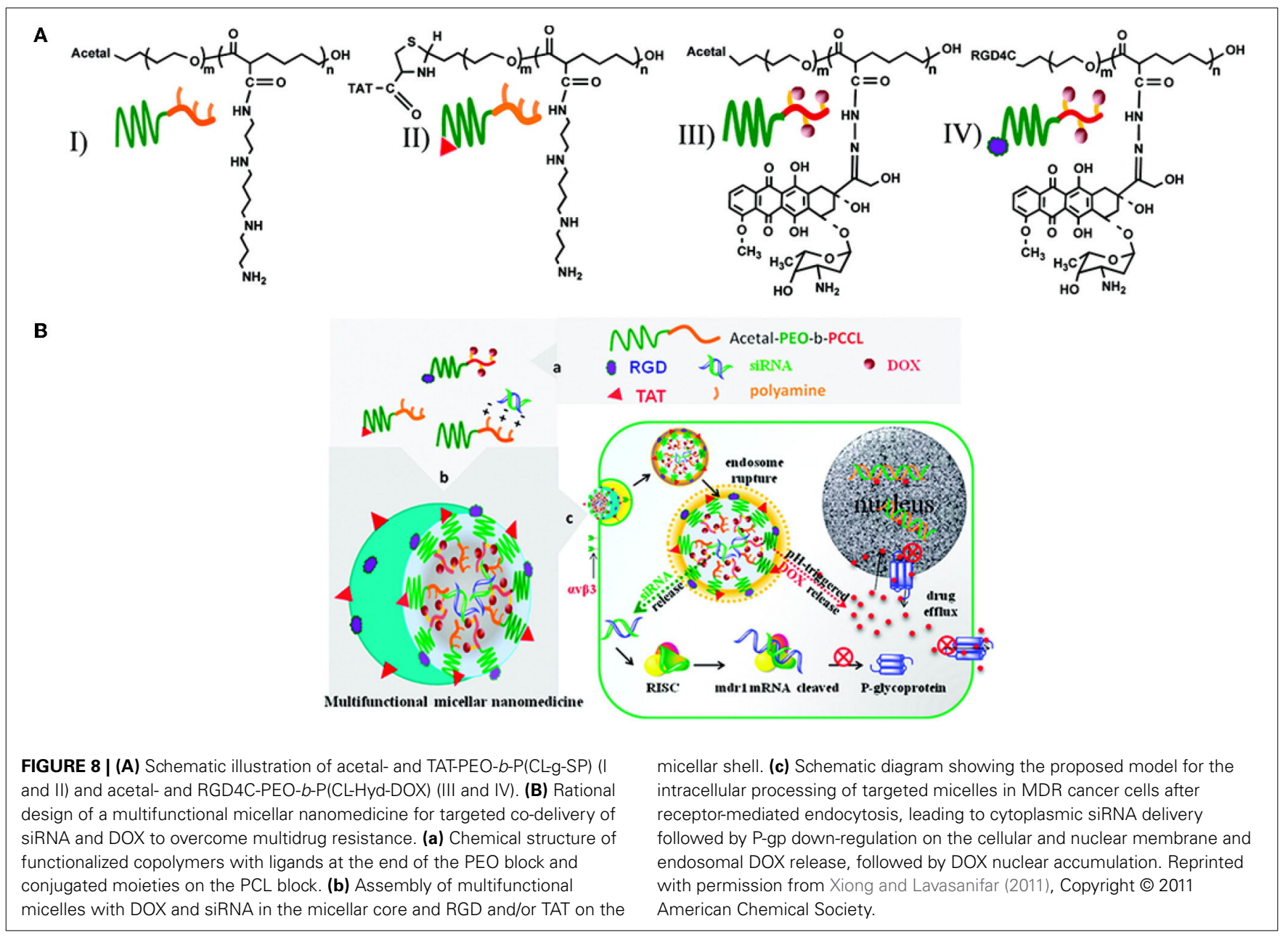

The final micelle formulation was obtained by mixing plain or peptide-modified PEO-b-P(CL-g-SP)/siRNA and PEO- $b$ $\mathrm{P}$ (CLHyd-DOX) block copolymers. The micelles were taken up by the cells through receptor-mediated endocytosis, and released siRNA in the cytoplasm due to endosomal rupture facilitated by spermine and TAT peptide. The traceable micelles were prepared by conjugating a near-infrared fluorophore (Cy5.5) (NIRF) to the spermine side chain or by using fluorescently labeled (Dy677) siRNA which allowed tracking of both the carrier as well as incorporated siRNA in vivo. The RGD/TAT-micelles containing MDR1-siRNA demonstrated significant cellular uptake, improved penetration and enhanced the cytotoxicity of DOX in DOX-resistant cells. The cytotoxicity was a result of downregulation of P-gp expression on cell and nuclear membranes caused by cytoplasmic delivery of siRNA and DOX (Xiong and Lavasanifar, 2011).

Zhao et al. reported on multifunctional micelles capable of codelivering docetaxel as well as siRNA against polo-like kinase 1 (Plk1), which is over-expressed in a number of tumors and plays a crucial role in cell mitosis (Zhao et al., 2013). The authors conjugated siPlk1 to D- $\alpha$-tocopheryl polyethylene glycol succinate (vitamin E TPGS or TPGS), a water soluble vitamin E derivative, using a disulfide bond to form TPGS-siPlk1. The disulfide bond was susceptible to high intracellular GSH concentrations, which caused the release of siPlk1 and also accelerated drug release due to reduced stability of micelles following cleavage of the disulfide bond. To develop Herceptin-conjugated micelles, a mixture of TPGS-siPlk1conjugate and TPGS or amine terminated TPGS (TPGS- $\mathrm{NH}_{2}$ ) was used at a designated ratio for co-delivery of siRNA and docetaxel (Figure 9).

The micelles were evaluated in vitro in cells expressing low (NIH3T3), moderate (MCF-7) or high levels of HER2 (SK-BR3). To functionalize micelles with Herceptin, TPGS- $\mathrm{NH}_{2}$ was used instead of TPGS followed by Herceptin conjugation via EDCNHS chemistry. The siPlk-1 and Herceptin modified micelles successfully internalized into the cytoplasm of SK-BR-3 cells. Moreover, the Herceptin modification enhanced the therapeutic efficacy of micelles due to its inherent toxicity to cancer cells as well as its ability to undergo receptor mediated endocytosis and assist the nanocarrier's entry into the cytoplasm. The Herceptin modified micelles showed significantly higher cellular uptake and low IC50 values in SK-BR-3 cells compared to micelles not modified with Herceptin (Zhao et al., 2013).

Another study also reported the delivery of siRNA against Plk-1 in combination with DOX to sensitize ovarian cancer cells (NCI/ADR-RES) to DOX (Benoit et al., 2010). The cationic 


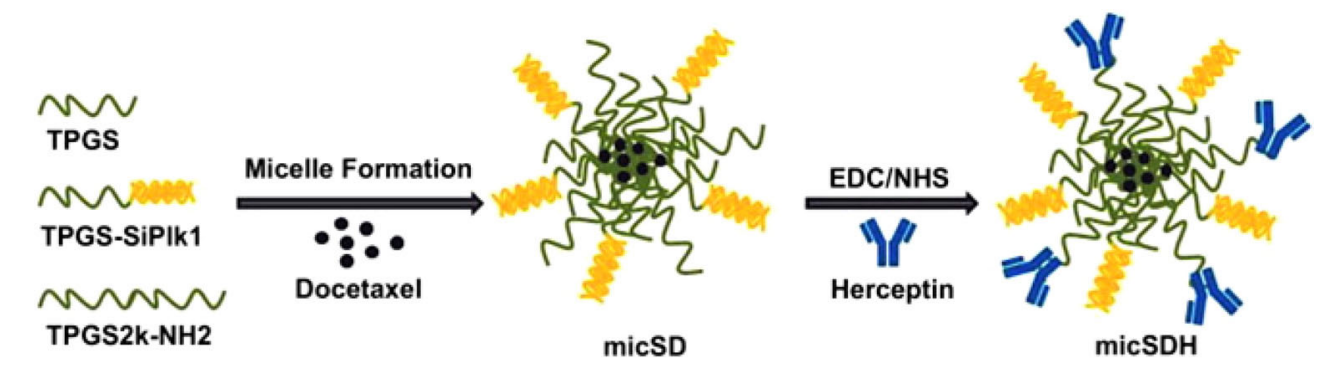

FIGURE 9 | Schematic illustration of formulation of the docetaxel loaded TPGS-siPIk1/TPGS micelles (micSD) and the herceptin-conjugated docetaxel loaded TPGS-siPIk1/TPGS micelles (micSDH). Reprinted from Zhao et al. (2013).

micelles were formed from diblock copolymers of dimethylaminoethyl methacrylate (pDMAEMA) and butyl methacrylate (BMA). The butyl core was responsible for micelle formation while the siRNA condensation was facilitated by the positively charged $\mathrm{p}$ (DMAEMA). A pH-responsive endosomolytic copolymer of poly(styrene-alt-maleic anhydride) (pSMA) was complexed to the positively charged siRNA/micelle to form a ternary complex by electrostatic interaction. DOX was loaded in the micelle cores to demonstrate simultaneous dual delivery with siRNA from a single carrier. However, for this particular study, the authors found that with dual delivery the effects on caspase activation and cell toxicity were weaker than those obtained with singly loaded siRNA ternary complexes due to a limitation in DOX loading concentration $(0.2 \mu \mathrm{g} / \mathrm{ml})$ (Benoit et al., 2010).

Cao et al. synthesized diblock copolymers of linear PEI and PCL (PEI-PCL) which self-assembled into cationic biodegradable polymeric micelles (Cao et al., 2011). Furthermore, the micelles were able to load and co-deliver anti-apoptotic Bcl-2 siRNA and DOX and utilized folic acid as a targeting agent for human hepatic cancer cells Bel-7402 (Figure 10). To incorporate folic acid, it was first conjugated to a polyion, poly(ethylene glycol)-blockpoly(glutamic acid) (FA-PEG-PGA) and then coated electrostatically onto the surface of cationic PEI-PCL micelles preloaded with siRNA and DOX. This multifunctional hierarchial nanoassembly was capable of simultaneous delivery of drug and siRNA in a targeted manner to yield a synergistic effect of RNAi and chemotherapy on cancer targets.

The approach for incorporation of folate was relatively simple, avoided the toxicity associated with cationic carriers and did not affect siRNA complexation. At certain ratios of PEI-PCL nitrogen -to-siRNA phosphate (N/P) and FA-PEG-PGA carboxyl-to-PEIPCL amine $(\mathrm{C} / \mathrm{N})$, the micelles demonstrated high transfection efficiency as well as controlled release of DOX. The folate-targeted delivery of anti-apoptotic Bcl-2 siRNA resulted in significant gene suppression at both the mRNA and protein expression levels compared to the non-targeted micelles. The suppression of DOX-inducible up-regulation of the anti-apoptotic Bcl-2 gene led to enhanced cell apoptosis in Bel-7402 cells and potentiated the effect of DOX in inducing cell death through a synergistic effect of siRNA and DOX (Cao et al., 2011). Following up on these promising in vitro results, the authors extended their research to determine if this multifunctional nanoplatform would show a synergistic effect in vivo, and to elucidate the molecular mechanism of the synergistic effect (Cheng et al., 2012). A rat model with an in situ C6 glioma implant was used for in vivo studies. In the in vitro studies the folate-targeted multifunctional micelles induced significant cell apoptosis in C6 cells even at a low dose of DOX $(0.5 \mu \mathrm{g} / \mathrm{mL})$ compared to free DOX, which caused apoptosis only at high doses $(15 \mu \mathrm{g} / \mathrm{mL})$. Molecular investigations showed that the targeted nanocarriers effectively suppressed the anti-apoptotic response induced by DOX, and sensitized C6 cells to DOX treatment both in vitro and in vivo. In the animal studies, the folate-targeted co-delivery of Bcl-2 siRNA and DOX caused a significant down-regulation of the $\mathrm{Bcl}-2$ gene and also up-regulated the pro-apoptotic Bax gene, which increased the activated caspase-3 levels significantly, resulting in cell apoptosis in the tumor tissues. The targeted co-delivery strategy led to a synergistic effect in vivo causing effective tumor growth inhibition as well as prolonged survival time over treatment with micelles with single agents or non-targeted micelles (Cheng et al., 2012). Zou et al. from the same group reported a triblock copolymer PEG-PEI-PCL instead of PEI-PCL mentioned above and conjugated it to FA. This copolymer self-assembled to form cationic micelles which could then complex Bcl-2 siRNA. These micelles simultaneously delivered siRNA and DOX with successful results in vitro in SKOV-3 ovarian cancer cells. This ternary copolymer complex was reported to have better stability than that formed using the hierarchial multilayer assembly where the PEG coating was achieved by electrostatic interaction rather than covalent linkage (Zou et al., 2012).

In a recent study, Zhu et al. reported the development of MMP-2 sensitive multifunctional polymeric micelles for the co-delivery of siRNA (anti-survivin or anti-GFP) and PTX (Zhu et al., 2014). They developed a simple MMP-2-sensitive self-assembling copolymer, PEG-pp-PEI-PE using a synthetic octapeptide (GPLGIAGQ) which was also utilized in their previous investigations with both, liposomes and micelles for MMP-2sensitive tumor targeting (Zhu et al., 2012, 2013). The micelles exhibited efficient down-regulation of the reporter gene (GFP) in GFP expressing cells (copGFP A549) and survivin in PTXresistant non-small cell lung cancer cells (A549 T24). The PEGpp-PEI-PE/PTX micelles significantly increased the cytotoxicity of PTX in both PTX-sensitive (A549) and resistant (A549 T24) cells relative to the free drug or non-sensitive micelles. The simultaneous delivery of anti-survivin siRNA and PTX resulted in a synergistic effect, significantly reducing the $\mathrm{IC}_{50}$ of PTX to $15 \mathrm{nM}$ 

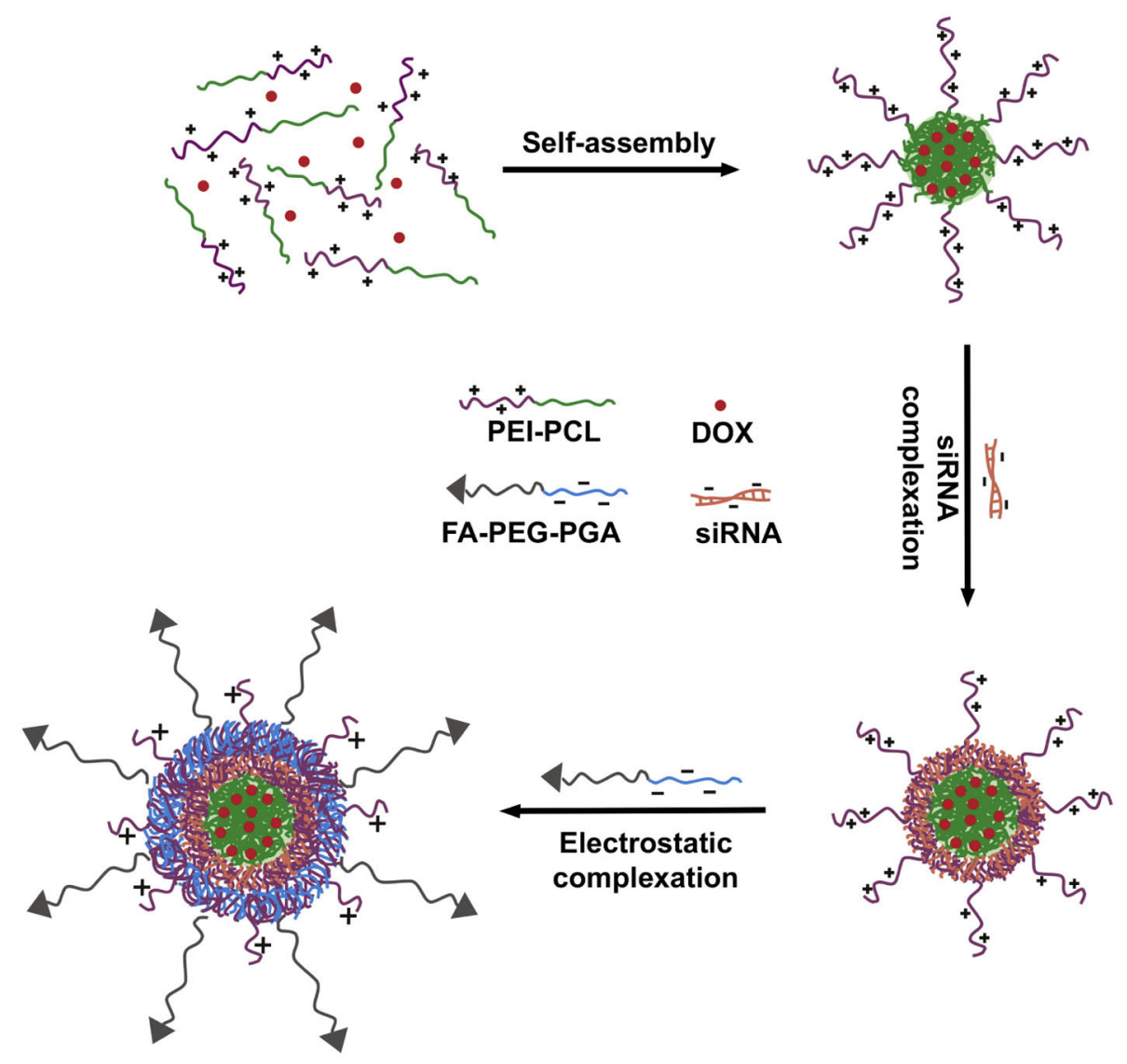

FIGURE 10 | Formation of hierarchical nano-assemblies for combinatorial delivery of siRNA and anticancer drugs. Reprinted from Cao et al. (2011).

(from $96 \mathrm{nM}$ for free PTX). In vivo, although the co-delivery efficacy for siRNA and PTX was not as pronounced as that under in vitro conditions, the MMP-2 sensitive micelles showed a 2.4-fold higher internalization of siRNA and PTX compared to the non-sensitive micelles due to the de-shielding of PEG and exposure of PEI (Zhu et al., 2014).

\section{CONCLUSIONS AND FUTURE DIRECTIONS}

The last several years have seen rapid advances in the use of polymeric micelles for delivery of a variety of cargoes from conventional anti-cancer drugs to biological macromolecules such as DNA, siRNA, antibodies and oligonucleotides. Chemical modifications in the structure of micelle-forming block copolymers have enabled the development of sophisticated micelles which combine multiple modalities within a single carrier. There is a clear shift from developing just single-therapeutic agent loaded micelles to micelles which combine more than one type of therapeutic payload and which can also be modified for active targeting, delivery of imaging agents and response to special cues provided either by the tumor microenvironment or externally, to spatially and temporally control the release of entrapped cargoes.

This review has discussed a number of examples which cover a wide range of polymeric micelle modifications-from polymeric micelles which are modified for passive targeting and rely on the EPR effect, to progressively more complex systems which incorporate targeting ligands, respond to various stimuli and finally to systems which simultaneously and seamlessly incorporate multiple modifications as well as combinations of drugs and biologics like siRNA to give rise to multifunctional polymeric micelles. We may certainly look to the future of polymeric micelles with a lot of optimism, given their inherent advantages and ease of introducing structural modifications. In part, this is supported by the wide variety of amphiphilic copolymers available for manipulation, better control of micelle characteristics and clinical success with passively targeted polymeric micelles for anti-cancer drugs. However, as far as siRNA delivery is concerned, much work remains before polymeric micelle therapeutics can be successfully translated into clinical usage. This stems from the inherent difficulty in delivering siRNA and a host of biological barriers encountered en route to its ultimate destination, the RNAi machinery in the cytoplasm. There exist certain established criteria for the successful development of polymeric micelles for siRNA delivery based on the previous as well as ongoing investigations. These include controlling the micelle size to be large enough to preclude renal filtration but small enough to avoid phagocytosis, chemical modifications of siRNA to improve stability against nuclease degradation and avoid immunostimulation, PEGylation to prevent rapid elimination, non-specific interactions and to 
evade immune surveillance, use of polycations in micelle blocks to effectively condense siRNA and improve transfection, incorporation of endosomolytic agents to assist the endosomal escape of siRNA, and finally the use of targeting ligands to improve uptake by specific cells (Kanasty et al., 2013). However, to arrive at an efficacious micellar formulation for siRNA, it is critical to optimize each of these parameters so that enhancing one of them does not adversely affect the other. For example, polycations enhance the condensation of siRNA in the micelles and improve its transfection efficacy, but may negatively affect the overall safety of the micelles in vitro and in vivo, which necessitates the use of low molecular weight polycations that are relatively safer to use. To date, many oncogenic targets including those involved in apoptosis, drug resistance, proliferation and angiogenesis have been investigated for siRNA-mediated therapy of cancer. However, the safe and efficient delivery of siRNA into target cells still presents a formidable challenge (Liu et al., 2013). We must address key challenges in siRNA delivery to optimize micelle formulations to enable their translation into clinically acceptable therapeutics. There is a need to develop polymers which allow efficient siRNA loading and protection within the formulation without the accompanying adverse effects. Efforts need to be focused on development of more stable micelle formulations with siRNA that allow long term storage if they are to eventually reach the clinics. In vivo safety issues like immune stimulation and offtarget effects of both siRNA and micelle forming materials need to be given serious consideration as well. The PK/PD parameters and biodistribution of siRNA after systemic administration must be studied systematically to arrive at optimal siRNA dosing regimens. Finally, studies must also be undertaken to investigate optimized ratios of drug and siRNA when loaded simultaneously in the same carrier to ensure their synergistic therapeutic effect (Liu et al., 2013).

Multifunctional micelles have gained immense popularity because of their versatility in simultaneously incorporating a variety of different payloads (therapeutic and imaging) and their ability to withstand multiple modifications (active and passive targeting, response to stimuli, imaging) to enable cancer cell specific targeting and therapy. In the light of what has been discussed, we can consider these "smart" polymeric micelles as our best current option for delivery of nucleic acid therapeutics, in particular, siRNA, albeit not without certain limitations. It is crucial to ensure that the functionalities incorporated within a polymeric micelle function seamlessly in perfect coordination with each other. With many different functions and modifications, the architecture of the micelles becomes more complex which can lead to difficulties in their reproducible synthesis and scale-up for manufacture. Impediments to clinical translation may result from the challenge in developing a robust manufacturing process, its cost effectiveness, and finally the regulatory requirements that have to be met when introducing a complex nanocarrier in the clinic. Incorporating siRNA along with drugs and various ligands within a multifunctional micelle may prove to be technically challenging on a large scale.

In spite of the evident hurdles, there are a number of elegantly designed multifunctional micellar formulations under active investigation, and as new technologies develop, there will be more data on such multifunctional platforms for further research. It is a well-known fact that the translational potential of a system increases if it has a simplified design and ease of development. To that end, polymeric micelles, like their nanocarrier counterparts, liposomes; are already well ahead of other nanocarriers in terms of proven clinical success. The challenge then remains to harness the success with passively targeted micelles to design elegant multifunctional polymeric micelles capable of delivering multiple therapeutic molecules simultaneously.

\section{REFERENCES}

Abouzeid, A. H., Patel, N. R., Rachman, I. M., Senn, S., and Torchilin, V. P. (2013). Anti-cancer activity of anti-GLUT1 antibody-targeted polymeric micelles coloaded with curcumin and doxorubicin. J. Drug Target. 21, 994-1000. doi: 10.3109/1061186X.2013.840639

Abouzeid, A. H., Patel, N. R., and Torchilin, V. P. (2014). Polyethylene glycolphosphatidylethanolamine (PEG-PE)/vitamin E micelles for co-delivery of paclitaxel and curcumin to overcome multi-drug resistance in ovarian cancer. Int. J. Pharm. 464, 178-184. doi: 10.1016/j.ijpharm.2014.01.009

Ai, J., Biazar, E., Jafarpour, M., Montazeri, M., Majdi, A., Aminifard, S., et al. (2011). Nanotoxicology and nanoparticle safety in biomedical designs. Int. J. Nanomedicine 6, 1117-1127. doi: 10.2147/IJN.S16603

Allen, T. M., and Cullis, P. R. (2004). Drug delivery systems: entering the mainstream. Science 303, 1818-1822. doi: 10.1126/science.1095833

Bailly, N., Thomas, M., and Klumperman, B. (2012). Poly(N-vinylpyrrolidone)block-poly(vinyl acetate) as a drug delivery vehicle for hydrophobic drugs. Biomacromolecules 13, 4109-4117. doi: 10.1021/bm301410d

Bastakoti, B. P., Wu, K. C., Inoue, M., Yusa, S., Nakashima, K., and Yamauchi, Y. (2013). Multifunctional core-shell-corona-type polymeric micelles for anticancer drug-delivery and imaging. Chemistry 19, 4812-4817. doi: 10.1002/chem. 201203958

Benoit, D. S., Henry, S. M., Shubin, A. D., Hoffman, A. S., and Stayton, P. S. (2010). $\mathrm{pH}$-responsive polymeric sirna carriers sensitize multidrug resistant ovarian cancer cells to doxorubicin via knockdown of polo-like kinase 1. Mol. Pharm. 7, 442-455. doi: 10.1021/mp9002255

Blanco, E., Kessinger, C. W., Sumer, B. D., and Gao, J. (2009). Multifunctional micellar nanomedicine for cancer therapy. Exp. Biol. Med. 234, 123-131. doi: 10.3181/0808-MR-250

Boissiere, O., Han, D., Tremblay, L., and Zhao, Y. (2011). Flower micelles of poly(Nisopropylacrylamide) with azobenzene moieties regularly inserted into the main chain. Soft Matter 7, 9410-9415. doi: 10.1039/c1sm06149f

Bumcrot, D., Manoharan, M., Koteliansky, V., and Sah, D. W. (2006). RNAi therapeutics: a potential new class of pharmaceutical drugs. Nat. Chem. Biol. 2, 711-719. doi: 10.1038/nchembio839

Cabral, H., Nishiyama, N., and Kataoka, K. (2007). Optimization of (1,2-diaminocyclohexane)platinum(II)-loaded polymeric micelles directed to improved tumor targeting and enhanced antitumor activity. J. Control. Release 121, 146-155. doi: 10.1016/j.jconrel.2007.05.024

Cabral, H., Nishiyama, N., Okazaki, S., Koyama, H., and Kataoka, K. (2005). Preparation and biological properties of dichloro(1,2diaminocyclohexane)platinum(II) (DACHPt)-loaded polymeric micelles. J. Control. Release 101, 223-232. doi: 10.1016/j.jconrel.2004.08.022

Cao, J., Huang, S., Chen, Y., Li, S., Li, X., Deng, D., et al. (2013). Near-infrared lighttriggered micelles for fast controlled drug release in deep tissue. Biomaterials 34, 6272-6283. doi: 10.1016/j.biomaterials.2013.05.008

Cao, N., Cheng, D., Zou, S., Ai, H., Gao, J., and Shuai, X. (2011). The synergistic effect of hierarchical assemblies of siRNA and chemotherapeutic drugs co-delivered into hepatic cancer cells. Biomaterials 32, 2222-2232. doi: 10.1016/j.biomaterials.2010.11.061

Casey, J. R., Grinstein, S., and Orlowski, J. (2010). Sensors and regulators of intracellular pH. Nat. Rev. Mol. Cell Biol. 11, 50-61. doi: 10.1038/nrm2820

Chen, W., Zhong, P., Meng, F., Cheng, R., Deng, C., Feijen, J., et al. (2013). Redox and $\mathrm{pH}$-responsive degradable micelles for dually activated intracellular anticancer drug release. J. Control. Release 169, 171-179. doi: 10.1016/j.jconrel.2013.01.001

Chen, Y. C., Liang, H. D., Zhang, Q. P., Blomley, M. J., and Lu, Q. L. (2006). Pluronic block copolymers: novel functions in ultrasound-mediated gene 
transfer and against cell damage. Ultrasound Med. Biol. 32, 131-137. doi: 10.1016/j.ultrasmedbio.2005.10.002

Chen, Z., He, Y., Wang, Y., and Wang, X. (2011). Amphiphilic diblock copolymer with dithienylethene pendants: synthesis and photo-modulated self-assembly. Macromol. Rapid Commun. 32, 977-982. doi: 10.1002/marc.201100142

Cheng, D., Cao, N., Chen, J., Yu, X., and Shuai, X. (2012). Multifunctional nanocarrier mediated co-delivery of doxorubicin and siRNA for synergistic enhancement of glioma apoptosis in rat. Biomaterials 33, 1170-1179. doi: 10.1016/j.biomaterials.2011.10.057

Cheng, R., Meng, F., Deng, C., Klok, H. A., and Zhong, Z. (2013). Dual and multistimuli responsive polymeric nanoparticles for programmed site-specific drug delivery. Biomaterials 34, 3647-3657. doi: 10.1016/j.biomaterials.2013.01.084

Chitkara, D., Mittal, A., Behrman, S. W., Kumar, N., and Mahato, R. I. (2013). Selfassembling, amphiphilic polymer-gemcitabine conjugate shows enhanced antitumor efficacy against human pancreatic adenocarcinoma. Bioconjug. Chem. 24, 1161-1173. doi: $10.1021 / \mathrm{bc} 400032 \mathrm{x}$

Choi, S. W., Lee, S. H., Mok, H., and Park, T. G. (2010). Multifunctional siRNA delivery system: polyelectrolyte complex micelles of six-arm PEG conjugate of siRNA and cell penetrating peptide with crosslinked fusogenic peptide. Biotechnol. Prog. 26, 57-63. doi: 10.1002/btpr.310.

Christie, R. J., Matsumoto, Y., Miyata, K., Nomoto, T., Fukushima, S., Osada, K., et al. (2012). Targeted polymeric micelles for siRNA treatment of experimental cancer by intravenous injection. ACS Nano 6, 5174-5189. doi: $10.1021 / \mathrm{nn} 300942 \mathrm{~b}$

Chung, E. J., Cheng, Y., Morshed, R., Nord, K., Han, Y., Wegscheid, M. L., et al. (2014). Fibrin-binding, peptide amphiphile micelles for targeting glioblastoma. Biomaterials 35, 1249-1256. doi: 10.1016/j.biomaterials.2013.10.064

Croy, S. R., and Kwon, G. S. (2006). Polymeric micelles for drug delivery. Curr. Pharm. Des. 12, 4669-4684. doi: 10.2174/138161206779026245

Dagar, A., Kuzmis, A., Rubinstein, I., Sekosan, M., and Onyuksel, H. (2012). VIPtargeted cytotoxic nanomedicine for breast cancer. Drug Deliv. Transl. Res. 2, 454-462. doi: 10.1007/s13346-012-0107-x

Daka, A., and Peer, D. (2012). RNAi-based nanomedicines for targeted personalized therapy. Adv. Drug Deliv. Rev. 64, 1508-1521. doi: 10.1016/j.addr.2012. 08.014

Danhier, F., Feron, O., and Preat, V. (2010). To exploit the tumor microenvironment: passive and active tumor targeting of nanocarriers for anti-cancer drug delivery. J. Control. Release 148, 135-146. doi: 10.1016/j.jconrel.2010.08.027

Danson, S., Ferry, D., Alakhov, V., Margison, J., Kerr, D., Jowle, D., et al. (2004). Phase I dose escalation and pharmacokinetic study of pluronic polymer-bound doxorubicin (SP1049C) in patients with advanced cancer. Br. J. Cancer 90, 2085-2091. doi: 10.1038/sj.bjc.6601856

Decuzzi, P., and Ferrari, M. (2008). The receptor-mediated endocytosis of nonspherical particles. Biophys. J. 94, 3790-3797. doi: 10.1529/biophysj.107.120238

De La Rica, R., Aili, D., and Stevens, M. M. (2012). Enzyme-responsive nanoparticles for drug release and diagnostics. Adv. Drug Deliv. Rev. 64, 967-978. doi: 10.1016/j.addr.2012.01.002

Desale, S. S., Cohen, S. M., Zhao, Y., Kabanov, A. V., and Bronich, T. K. (2013). Biodegradable hybrid polymer micelles for combination drug therapy in ovarian cancer. J. Control. Release 171, 339-348. doi: 10.1016/j.jconrel.2013.04.026

Di, L., Fish, P. V., and Mano, T. (2012). Bridging solubility between drug discovery and development. Drug Discov. Today 17, 486-495. doi: 10.1016/j.drudis.2011.11.007

Di, L., Kerns, E. H., and Carter, G. T. (2009). Drug-like property concepts in pharmaceutical design. Curr. Pharm. Des. 15, 2184-2194. doi: $10.2174 / 138161209788682479$

Dimitrov, I., Trzebicka, B., Müller, A. H. E., Dworak, A., and Tsvetanov, C. B. (2007). Thermosensitive water-soluble copolymers with doubly responsive reversibly interacting entities. Prog. Polym. Sci. 32, 1275-1343. doi: 10.1016/j.progpolymsci.2007.07.001

Ding, M., Song, N., He, X., Li, J., Zhou, L., Tan, H., et al. (2013). Toward the nextgeneration nanomedicines: design of multifunctional multiblock polyurethanes for effective cancer treatment. ACS Nano 7, 1918-1928. doi: 10.1021/nn4002769

Dominska, M., and Dykxhoorn, D. M. (2010). Breaking down the barriers: siRNA delivery and endosome escape. J. Cell Sci. 123, 1183-1189. doi: 10.1242/jcs.066399

Du, Y. Z., Weng, Q., Yuan, H., and Hu, F. Q. (2010). Synthesis and antitumor activity of stearate-g-dextran micelles for intracellular doxorubicin delivery. ACS Nano 4, 6894-6902. doi: 10.1021/nn100927t
Duncan, R., and Gaspar, R. (2011). Nanomedicine(s) under the microscope. Mol. Pharm. 8, 2101-2141. doi: 10.1021/mp200394t

Duong, H. H., and Yung, L. Y. (2013). Synergistic co-delivery of doxorubicin and paclitaxel using multi-functional micelles for cancer treatment. Int. J. Pharm. 454, 486-495. doi: 10.1016/j.ijpharm.2013.06.017

Elbashir, S. M., Harborth, J., Lendeckel, W., Yalcin, A., Weber, K., and Tuschl, T. (2001). Duplexes of 21-nucleotide RNAs mediate RNA interference in cultured mammalian cells. Nature 411, 494-498. doi: 10.1038/35078107

Elsabahy, M., Wazen, N., Bayó-Puxan, N., Deleavey, G., Servant, M., Damha, M. J., et al. (2009). Delivery of nucleic acids through the controlled disassembly of multifunctional nanocomplexes. Adv. Funct. Mater. 19, 3862-3867. doi: 10.1002/adfm.200901139

Elsaesser, A., and Howard, C. V. (2012). Toxicology of nanoparticles. Adv. Drug Deliv. Rev. 64, 129-137. doi: 10.1016/j.addr.2011.09.001

Falamarzian, A., Xiong, X.-B., Uludag, H., and Lavasanifar, A. (2012). Polymeric micelles for siRNA delivery. J. Drug Deliv. Sci. Technol. 22, 43-54.

Fang, J., Nakamura, H., and Maeda, H. (2011). The EPR effect: unique features of tumor blood vessels for drug delivery, factors involved, and limitations and augmentation of the effect. Adv. Drug Deliv. Rev. 63, 136-151. doi: 10.1016/j.addr.2010.04.009

Felber, A. E., Castagner, B., Elsabahy, M., Deleavey, G. F., Damha, M. J., and Leroux, J. C. (2011). siRNA nanocarriers based on methacrylic acid copolymers. J. Control. Release 152, 159-167. doi: 10.1016/j.jconrel.2010.12.012

Felber, A. E., Dufresne, M. H., and Leroux, J. C. (2012). pH-sensitive vesicles, polymeric micelles, and nanospheres prepared with polycarboxylates. Adv. Drug Deliv. Rev. 64, 979-992. doi: 10.1016/j.addr.2011.09.006

Fernandez, A. M., Van Derpoorten, K., Dasnois, L., Lebtahi, K., Dubois, V., Lobl, T. J., et al. (2001). N-Succinyl-(beta-alanyl-L-leucyl-L-alanyl-Lleucyl)doxorubicin: an extracellularly tumor-activated prodrug devoid of intravenous acute toxicity. J. Med. Chem. 44, 3750-3753. doi: 10.1021/jm01 08754

Fire, A., Xu, S. Q., Montgomery, M. K., Kostas, S. A., Driver, S. E., and Mello, C. C. (1998). Potent and specific genetic interference by double-stranded RNA in Caenorhabditis elegans. Nature 391, 806-811. doi: 10.1038/35888

Firer, M. A., and Gellerman, G. (2012). Targeted drug delivery for cancer therapy: the other side of antibodies. J. Hematol. Oncol. 5:70. doi: 10.1186/17568722-5-70

Fleige, E., Quadir, M. A., and Haag, R. (2012). Stimuli-responsive polymeric nanocarriers for the controlled transport of active compounds: concepts and applications. Adv. Drug Deliv. Rev. 64, 866-884. doi: 10.1016/j.addr.2012. 01.020

Folkman, J. (1995). Angiogenesis in cancer, vascular, rheumatoid and other disease. Nat. Med. 1, 27-31. doi: 10.1038/nm0195-27

Fomina, N., Sankaranarayanan, J., and Almutairi, A. (2012). Photochemical mechanisms of light-triggered release from nanocarriers. Adv. Drug Deliv. Rev. 64, 1005-1020. doi: 10.1016/j.addr.2012.02.006

Fonge, H., Huang, H., Scollard, D., Reilly, R. M., and Allen, C. (2012). Influence of formulation variables on the biodistribution of multifunctional block copolymer micelles. J. Control. Release 157, 366-374. doi: 10.1016/j.jconrel.2011.09.088

Freichels, H., Alaimo, D., Auzely-Velty, R., and Jerome, C. (2012). alpha-Acetal, omega-alkyne poly(ethylene oxide) as a versatile building block for the synthesis of glycoconjugated graft-copolymers suited for targeted drug delivery. Bioconjug. Chem. 23, 1740-1752. doi: 10.1021/bc200650n

Ganta, S., Devalapally, H., Shahiwala, A., and Amiji, M. (2008). A review of stimuliresponsive nanocarriers for drug and gene delivery. J. Control. Release 126, 187-204. doi: 10.1016/j.jconrel.2007.12.017

Gerweck, L. E., and Seetharaman, K. (1996). Cellular pH gradient in tumor versus normal tissue: potential exploitation for the treatment of cancer. Cancer Res. 56, 1194-1198.

Glover, A. L., Bennett, J. B., Pritchett, J. S., Nikles, S. M., Nikles, D. E., Nikles, J. A., et al. (2013). Magnetic heating of iron oxide nanoparticles and magnetic micelles for cancer therapy. IEEE Trans. Magn. 49, 231-235. doi: 10.1109/TMAG.2012.2222359

Gohy, J. F., and Zhao, Y. (2013). Photo-responsive block copolymer micelles: design and behavior. Chem. Soc. Rev. 42, 7117-7129. doi: 10.1039/c3cs35469e

Goldenberg, D. M., and Sharkey, R. M. (2012). Using antibodies to target cancer therapeutics. Expert Opin. Biol. Ther. 12, 1173-1190. doi: $10.1517 / 14712598.2012 .693472$ 
Gülçür, E., Thaqi, M., Khaja, F., Kuzmis, A., and Önyüksel, H. (2013). Curcumin in VIP-targeted sterically stabilized phospholipid nanomicelles: a novel therapeutic approach for breast cancer and breast cancer stem cells. Drug Deliv. Transl. Res. 3, 562-574. doi: 10.1007/s13346-013-0167-6

Guo, J., Hong, H., Chen, G., Shi, S., Zheng, Q., Zhang, Y., et al. (2013). Imageguided and tumor-targeted drug delivery with radiolabeled unimolecular micelles. Biomaterials 34, 8323-8332. doi: 10.1016/j.biomaterials.2013.07.085

Hamaguchi, T., Kato, K., Yasui, H., Morizane, C., Ikeda, M., Ueno, H., et al. (2007). A phase I and pharmacokinetic study of NK105, a paclitaxelincorporating micellar nanoparticle formulation. Br. J. Cancer 97, 170-176. doi: 10.1038/sj.bjc. 6603855

Hami, Z., Amini, M., Ghazi-Khansari, M., Rezayat, S. M., and Gilani, K. (2014). Synthesis and in vitro evaluation of a $\mathrm{pH}$-sensitive PLA-PEG-folate based polymeric micelle for controlled delivery of docetaxel. Colloids Surf. B Biointerfaces 116C, 309-317. doi: 10.1016/j.colsurfb.2014.01.015

Hannon, G. J. (2002). RNA interference. Nature 418, 244-251. doi: $10.1038 / 418244 \mathrm{a}$

Hatakeyama, H., Akita, H., and Harashima, H. (2011). A multifunctional envelope type nano device (MEND) for gene delivery to tumours based on the EPR effect: a strategy for overcoming the PEG dilemma. Adv. Drug Deliv. Rev. 63, 152-160. doi: 10.1016/j.addr.2010.09.001

Hoang, B., Ekdawi, S. N., Reilly, R. M., and Allen, C. (2013). Active targeting of block copolymer micelles with trastuzumab fab fragments and nuclear localization signal leads to increased tumor uptake and nuclear localization in HER2-overexpressing xenografts. Mol. Pharm. 10, 4229-4241. doi: 10.1021/mp400315p

Hobbs, S. K., Monsky, W. L., Yuan, F., Roberts, W. G., Griffith, L., Torchilin, V. P., et al. (1998). Regulation of transport pathways in tumor vessels: role of tumor type and microenvironment. Proc. Natl. Acad. Sci. U.S.A. 95, 4607-4612. doi: 10.1073/pnas.95.8.4607

Holliger, P., and Hudson, P. J. (2005). Engineered antibody fragments and the rise of single domains. Nat. Biotechnol. 23, 1126-1136. doi: 10.1038/nbt1142

Hossain, M. D. D., Tran, L. T. B., Park, J. M., and Lim, K. T. (2010). Facile synthesis of core-surface crosslinked nanoparticles by interblock RAFT polymerization. J. Polym. Sci. A Polym. Chem. 48, 4958-4964. doi: 10.1002/pola.24291

Howell, M., Mallela, J., Wang, C., Ravi, S., Dixit, S., Garapati, U., et al. (2013). Manganese-loaded lipid-micellar theranostics for simultaneous drug and gene delivery to lungs. J. Control. Release 167, 210-218. doi: 10.1016/j.jconrel.2013.01.029

Hu, J., Zhang, G., and Liu, S. (2012). Enzyme-responsive polymeric assemblies, nanoparticles and hydrogels. Chem. Soc. Rev. 41, 5933-5949. doi: $10.1039 / \mathrm{c} 2 \mathrm{cs} 35103 \mathrm{j}$

Huang, C., Tang, Z., Zhou, Y., Zhou, X., Jin, Y., Li, D., et al. (2012). Magnetic micelles as a potential platform for dual targeted drug delivery in cancer therapy. Int. J. Pharm. 429, 113-122. doi: 10.1016/j.ijpharm.2012.03.001

Husseini, G. A., and Pitt, W. G. (2008a). Micelles and nanoparticles for ultrasonic drug and gene delivery. Adv. Drug Deliv. Rev. 60, 1137-1152. doi: 10.1016/j.addr.2008.03.008

Husseini, G. A., and Pitt, W. G. (2008b). The use of ultrasound and micelles in cancer treatment. J. Nanosci. Nanotechnol. 8, 2205-2215. doi: 10.1166/jnn.2008.225

Husseini, G. A., Pitt, W. G., Christensen, D. A., and Dickinson, D. J. (2009). Degradation kinetics of stabilized Pluronic micelles under the action of ultrasound. J. Control. Release 138, 45-48. doi: 10.1016/j.jconrel.2009.04.018

Husseini, G. A., Velluto, D., Kherbeck, L., Pitt, W. G., Hubbell, J. A., and Christensen, D. A. (2013). Investigating the acoustic release of doxorubicin from targeted micelles. Colloids Surf. B Biointerfaces 101, 153-155. doi: 10.1016/j.colsurfb.2012.05.025

Iyer, A. K., Khaled, G., Fang, J., and Maeda, H. (2006). Exploiting the enhanced permeability and retention effect for tumor targeting. Drug Discov. Today 11, 812-818. doi: 10.1016/j.drudis.2006.07.005

Jabr-Milane, L. S., Van Vlerken, L. E., Yadav, S., and Amiji, M. M. (2008). Multifunctional nanocarriers to overcome tumor drug resistance. Cancer Treat. Rev. 34, 592-602. doi: 10.1016/j.ctrv.2008.04.003

Jain, R. K. (1987). Transport of molecules across tumor vasculature. Cancer Metastasis Rev. 6, 559-593. doi: 10.1007/BF00047468

Jin, C., Yang, W., Bai, L., Wang, J., and Dou, K. (2011a). Preparation and characterization of targeted DOX-PLGA-PEG micelles decorated with bivalent fragment HAb18 F(ab')2 for treatment of hepatocellular carcinoma. J. Control. Release 152(Suppl. 1), e14-e15. doi: 10.1016/j.jconrel.2011.08.093
Jin, Q., Mitschang, F., and Agarwal, S. (2011b). Biocompatible drug delivery system for photo-triggered controlled release of 5-Fluorouracil. Biomacromolecules 12 , 3684-3691. doi: 10.1021/bm2009125

Jones, M., and Leroux, J. (1999). Polymeric micelles—a new generation of colloidal drug carriers. Eur. J. Pharm. Biopharm. 48, 101-111. doi: 10.1016/S09396411(99)00039-9

Kabanov, A. V., Batrakova, E. V., and Alakhov, V. Y. (2002). Pluronic block copolymers as novel polymer therapeutics for drug and gene delivery. J. Control. Release 82, 189-212. doi: 10.1016/S0168-3659(02)00009-3

Kagaya, H., Oba, M., Miura, Y., Koyama, H., Ishii, T., Shimada, T., et al. (2012). Impact of polyplex micelles installed with cyclic RGD peptide as ligand on gene delivery to vascular lesions. Gene Ther. 19, 61-69. doi: 10.1038/gt.2011.74

Kamaly, N., Xiao, Z., Valencia, P. M., Radovic-Moreno, A. F., and Farokhzad, O. C. (2012). Targeted polymeric therapeutic nanoparticles: design, development and clinical translation. Chem. Soc. Rev. 41, 2971-3010. doi: 10.1039/c2cs15344k

Kanasty, R., Dorkin, J. R., Vegas, A., and Anderson, D. (2013). Delivery materials for siRNA therapeutics. Nat. Mater. 12, 967-977. doi: 10.1038/nmat3765

Kanasty, R. L., Whitehead, K. A., Vegas, A. J., and Anderson, D. G. (2012). Action and reaction: the biological response to siRNA and its delivery vehicles. Mol. Ther. 20, 513-524. doi: 10.1038/mt.2011.294

Kanazawa, T., Akiyama, F., Kakizaki, S., Takashima, Y., and Seta, Y. (2013). Delivery of siRNA to the brain using a combination of nose-to-brain delivery and cellpenetrating peptide-modified nano-micelles. Biomaterials 34, 9220-9226. doi: 10.1016/j.biomaterials.2013.08.036

Kanazawa, T., Sugawara, K., Tanaka, K., Horiuchi, S., Takashima, Y., and Okada, H. (2012). Suppression of tumor growth by systemic delivery of anti-VEGF siRNA with cell-penetrating peptide-modified MPEG-PCL nanomicelles. Eur. J. Pharm. Biopharm. 81, 470-477. doi: 10.1016/j.ejpb.2012.04.021

Kang, H., Lee, E., Na, K., and Bae, Y. (2008). "Stimuli-sensitive nanosystems: for drug and gene delivery," in Multifunctional Pharmaceutical Nanocarriers, ed V. Torchilin (New York, NY: Springer), 161-199.

Kato, K., Chin, K., Yoshikawa, T., Yamaguchi, K., Tsuji, Y., Esaki, T., et al. (2012). Phase II study of NK105, a paclitaxel-incorporating micellar nanoparticle, for previously treated advanced or recurrent gastric cancer. Invest. New Drugs 30, 1621-1627. doi: 10.1007/s10637-011-9709-2

Kim, D. H., Vitol, E. A., Liu, J., Balasubramanian, S., Gosztola, D. J., Cohen, E. E., et al. (2013). Stimuli-responsive magnetic nanomicelles as multifunctional heat and cargo delivery vehicles. Langmuir 29, 7425-7432. doi: 10.1021/la3044158

Kim, S. H., Jeong, J. H., Lee, S. H., Kim, S. W., and Park, T. G. (2008). Local and systemic delivery of VEGF siRNA using polyelectrolyte complex micelles for effective treatment of cancer. J. Control. Release 129, 107-116. doi: 10.1016/j.jconrel.2008.03.008

Kim, T. Y., Kim, D. W., Chung, J. Y., Shin, S. G., Kim, S. C., Heo, D. S., et al. (2004). Phase I and pharmacokinetic study of Genexol-PM, a cremophor-free, polymeric micelle-formulated paclitaxel, in patients with advanced malignancies. Clin. Cancer Res. 10, 3708-3716. doi: 10.1158/1078-0432.CCR-03-0655

Kirpotin, D. B., Drummond, D. C., Shao, Y., Shalaby, M. R., Hong, K., Nielsen, U. B., et al. (2006). Antibody targeting of long-circulating lipidic nanoparticles does not increase tumor localization but does increase internalization in animal models. Cancer Res. 66, 6732-6740. doi: 10.1158/0008-5472.CAN-05-4199

Koizumi, F., Kitagawa, M., Negishi, T., Onda, T., Matsumoto, S., Hamaguchi, T., et al. (2006). Novel SN-38-incorporating polymeric micelles, NK012, eradicate vascular endothelial growth factor-secreting bulky tumors. Cancer Res. 66, 10048-10056. doi: 10.1158/0008-5472.CAN-06-1605

Koo, A. N., Min, K. H., Lee, H. J., Lee, S. U., Kim, K., Kwon, I. C., et al. (2012). Tumor accumulation and antitumor efficacy of docetaxel-loaded core-shellcorona micelles with shell-specific redox-responsive cross-links. Biomaterials 33, 1489-1499. doi: 10.1016/j.biomaterials.2011.11.013

Koyamatsu, Y., Hirano, T., Kakizawa, Y., Okano, F., Takarada, T., and Maeda, M. (2013). pH-responsive release of proteins from biocompatible and biodegradable reverse polymer micelles. J. Control. Release 173C, 89-95. doi: 10.1016/j.jconrel.2013.10.035

Kumar, S., Allard, J.-F., Morris, D., Dory, Y. L., Lepage, M., and Zhao, Y. (2012). Near-infrared light sensitive polypeptide block copolymer micelles for drug delivery. J. Mater. Chem. 22, 7252-7257. doi: 10.1039/c2jm16380b

Laouini, A., Koutroumanis, K. P., Charcosset, C., Georgiadou, S., Fessi, H., Holdich, R. G., et al. (2013). pH-sensitive micelles for targeted drug delivery prepared using a novel membrane contactor method. ACS Appl. Mater. Interfaces 5, 8939-8947. doi: 10.1021/am4018237 
Leamon, C. P., and Low, P. S. (1991). Delivery of macromolecules into living cells: a method that exploits folate receptor endocytosis. Proc. Natl. Acad. Sci. U.S.A. 88, 5572-5576. doi: 10.1073/pnas.88.13.5572

Lee, A. L., Wang, Y., Pervaiz, S., Fan, W., and Yang, Y. Y. (2011a). Synergistic anticancer effects achieved by co-delivery of TRAIL and paclitaxel using cationic polymeric micelles. Macromol. Biosci. 11, 296-307. doi: 10.1002/mabi.201000332

Lee, I., Park, M., Kim, Y., Hwang, O., Khang, G., and Lee, D. (2013). Ketal containing amphiphilic block copolymer micelles as $\mathrm{pH}$-sensitive drug carriers. Int. J. Pharm. 448, 259-266. doi: 10.1016/j.ijpharm.2013.03.017

Lee, S. H., Mok, H., Lee, Y., and Park, T. G. (2011b). Self-assembled siRNA-PLGA conjugate micelles for gene silencing. J. Control. Release 152, 152-158. doi: 10.1016/j.jconrel.2010.12.007

Lewis, C. E., and Pollard, J. W. (2006). Distinct role of macrophages in different tumor microenvironments. Cancer Res. 66, 605-612. doi: 10.1158/00085472.CAN-05-4005

Li, G., Meng, Y., Guo, L., Zhang, T., and Liu, J. (2013a). Formation of thermo-sensitive polyelectrolyte complex micelles from two biocompatible graft copolymers for drug delivery. J. Biomed. Mater. Res. A. doi: 10.1002/jbm.a. 34894. [Epub ahead of print].

Li, J., Cheng, D., Yin, T., Chen, W., Lin, Y., Chen, J., et al. (2014). Copolymer of poly(ethylene glycol) and poly(l-lysine) grafting polyethylenimine through a reducible disulfide linkage for siRNA delivery. Nanoscale 6, 1732-1740. doi: 10.1039/c3nr05024f

Li, J., Ge, Z., and Liu, S. (2013b). PEG-sheddable polyplex micelles as smart gene carriers based on MMP-cleavable peptide-linked block copolymers. Chem. Commun. (Camb.) 49, 6974-6976. doi: 10.1039/c3cc43576h

Li, J., Huo, M., Wang, J., Zhou, J., Mohammad, J. M., Zhang, Y., et al. (2012a). Redox-sensitive micelles self-assembled from amphiphilic hyaluronic aciddeoxycholic acid conjugates for targeted intracellular delivery of paclitaxel. Biomaterials 33, 2310-2320. doi: 10.1016/j.biomaterials.2011.11.022

Li, W., Zhao, H., Qian, W., Li, H., Zhang, L., Ye, Z., et al. (2012b). Chemotherapy for gastric cancer by finely tailoring anti-Her2 anchored dual targeting immunomicelles. Biomaterials 33, 5349-5362. doi: 10.1016/j.biomaterials.2012. 04.016

Li, X., Li, H., Yi, W., Chen, J., and Liang, B. (2013c). Acid-triggered core crosslinked nanomicelles for targeted drug delivery and magnetic resonance imaging in liver cancer cells. Int. J. Nanomedicine 8, 3019-3031. doi: 10.2147/IJN.S45767

Li, Y., Gao, G. H., and Lee, D. S. (2013d). Stimulus-sensitive polymeric nanoparticles and their applications as drug and gene carriers. Adv. Healthc. Mater. 2, 388-417. doi: 10.1002/adhm.201200313

Li, Y., Liu, T., Zhang, G., Ge, Z., and Liu, S. (2013e). Tumor-targeted redoxresponsive nonviral gene delivery nanocarriers based on neutral-cationic brush block copolymers. Macromol. Rapid Commun. 35, 466-473. doi: 10.1002/marc.201300719

Li, Y., Ma, J., Zhu, H., Gao, X., Dong, H., and Shi, D. (2013f). Green synthetic, multifunctional hybrid micelles with shell embedded magnetic nanoparticles for theranostic applications. ACS Appl. Mater. Interfaces 5, 7227-7235. doi: 10.1021/am401573b

Li, Y., Qian, Y., Liu, T., Zhang, G., and Liu, S. (2012c). Light-triggered concomitant enhancement of magnetic resonance imaging contrast performance and drug release rate of functionalized amphiphilic diblock copolymer micelles. Biomacromolecules 13, 3877-3886. doi: 10.1021/bm301425j

Li, Y., Xiao, K., Luo, J., Xiao, W., Lee, J. S., Gonik, A. M., et al. (2011). Well-defined, reversible disulfide cross-linked micelles for on-demand paclitaxel delivery. Biomaterials 32, 6633-6645. doi: 10.1016/j.biomaterials.2011.05.050

Li, Y., Yang, F., Chen, W., Liu, J., Huang, W., Jin, M., et al. (2012d). A novel monomethoxy polyethylene glycol-polylactic acid polymeric micelles with higher loading capacity for docetaxel and well-reconstitution characteristics and its anti-metastasis study. Chem. Pharm. Bull. (Tokyo) 60, 1146-1154. doi: $10.1248 /$ cpb.c12-00323

Liao, C., Sun, Q., Liang, B., Shen, J., and Shuai, X. (2011). Targeting EGFRoverexpressing tumor cells using Cetuximab-immunomicelles loaded with doxorubicin and superparamagnetic iron oxide. Eur. J. Radiol. 80, 699-705. doi: 10.1016/j.ejrad.2010.08.005

Lin, G. Y., Lv, H. F., Lu, C. T., Chen, L. J., Lin, M., Zhang, M., et al. (2013). Construction and application of biotin-poloxamer conjugate micelles for chemotherapeutics. J. Microencapsul. 30, 538-545. doi: $10.3109 / 02652048.2012 .758182$
Liu, G.-Y., Chen, C.-J., Li, D.-D., Wang, S.-S., and Ji, J. (2012). Near-infrared lightsensitive micelles for enhanced intracellular drug delivery. J. Mater. Chem. 22, 16865-16871. doi: 10.1039/c2jm00045h

Liu, X.-Q., Sun, C.-Y., Yang, X.-Z., and Wang, J. (2013). Polymeric-Micelle-Based Nanomedicine for siRNA Delivery. Part. Part. Syst. Charact. 30, 211-228. doi: 10.1002/ppsc.201200061

Liu, Z., and Zhang, N. (2012). pH-Sensitive polymeric micelles for programmable drug and gene delivery. Curr. Pharm. Des. 18, 3442-3451. doi: $10.2174 / 138161212801227122$

Lu, Y., and Park, K. (2013). Polymeric micelles and alternative nanonized delivery vehicles for poorly soluble drugs. Int. J. Pharm. 453, 198-214. doi: 10.1016/j.ijpharm.2012.08.042

Macdiarmid, J. A., Amaro-Mugridge, N. B., Madrid-Weiss, J., Sedliarou, I., Wetzel, S., Kochar, K., et al. (2009). Sequential treatment of drug-resistant tumors with targeted minicells containing siRNA or a cytotoxic drug. Nat. Biotechnol. 27, 643-651. doi: 10.1038/nbt.1547

Maeda, H., Wu, J., Sawa, T., Matsumura, Y., and Hori, K. (2000). Tumor vascular permeability and the EPR effect in macromolecular therapeutics: a review. J. Control. Release 65, 271-284. doi: 10.1016/S0168-3659(99)00248-5

Mahmud, A., Xiong, X. B., Aliabadi, H. M., and Lavasanifar, A. (2007). Polymeric micelles for drug targeting. J. Drug Target. 15, 553-584. doi: 10.1080/10611860701538586

Martinez, J., Patkaniowska, A., Urlaub, H., Luhrmann, R., and Tuschl, T. (2002). Single-stranded antisense siRNAs guide target RNA cleavage in RNAi. Cell 110, 563-574. doi: 10.1016/S0092-8674(02)00908-X

Matsumoto, S., Christie, R. J., Nishiyama, N., Miyata, K., Ishii, A., Oba, M., et al. (2008). Environment-responsive block copolymer micelles with a disulfide cross-linked core for enhanced siRNA delivery. Biomacromolecules 10, 119-127. doi: 10.1021/bm800985e

Matsumoto, S., Christie, R. J., Nishiyama, N., Miyata, K., Ishii, A., Oba, M., et al. (2009). Environment-responsive block copolymer micelles with a disulfide cross-linked core for enhanced siRNA delivery. Biomacromolecules 10, 119-127. doi: 10.1021/bm800985e

Matsumura, Y., Hamaguchi, T., Ura, T., Muro, K., Yamada, Y., Shimada, Y., et al. (2004). Phase I clinical trial and pharmacokinetic evaluation of NK911, a micelle-encapsulated doxorubicin. Br. J. Cancer 91, 1775-1781. doi: 10.1038/sj.bjc.6602204

Matsumura, Y., and Maeda, H. (1986). A new concept for macromolecular therapeutics in cancer chemotherapy: mechanism of tumoritropic accumulation of proteins and the antitumor agent smancs. Cancer Res. 46, 6387-6392.

Meister, G., and Tuschl, T. (2004). Mechanisms of gene silencing by doublestranded RNA. Nature 431, 343-349. doi: 10.1038/nature02873

Menon, S., Thekkayil, R., Varghese, S., and Das, S. (2011). Photoresponsive soft materials: synthesis and photophysical studies of a stilbene-based diblock copolymer. J. Polym. Sci. A Polym. Chem. 49, 5063-5073. doi: 10.1002/pola.24973

Min, K. H., Kim, J. H., Bae, S. M., Shin, H., Kim, M. S., Park, S., et al. (2010). Tumoral acidic pH-responsive MPEG-poly(beta-amino ester) polymeric micelles for cancer targeting therapy. J. Control. Release 144, 259-266. doi: 10.1016/j.jconrel.2010.02.024

Miura, Y., Takenaka, T., Toh, K., Wu, S., Nishihara, H., Kano, M. R., et al. (2013). Cyclic RGD-linked polymeric micelles for targeted delivery of platinum anticancer drugs to glioblastoma through the blood-brain tumor barrier. ACS nano 7, 8583-8592. doi: 10.1021/nn402662d

Mohan, P., and Rapoport, N. (2010). Doxorubicin as a molecular nanotheranostic agent: effect of doxorubicin encapsulation in micelles or nanoemulsions on the ultrasound-mediated intracellular delivery and nuclear trafficking. Mol. Pharm. 7, 1959-1973. doi: 10.1021/mp100269f

Monsky, W. L., Fukumura, D., Gohongi, T., Ancukiewcz, M., Weich, H. A., Torchilin, V. P., et al. (1999). Augmentation of transvascular transport of macromolecules and nanoparticles in tumors using vascular endothelial growth factor. Cancer Res. 59, 4129-4135.

Mori, T. (2004). Cancer-specific ligands identified from screening of peptide-display libraries. Curr. Pharm. Des. 10, 2335-2343. doi: $10.2174 / 1381612043383944$

Mura, S., Nicolas, J., and Couvreur, P. (2013). Stimuli-responsive nanocarriers for drug delivery. Nat. Mater. 12, 991-1003. doi: 10.1038/nmat3776

Musacchio, T., and Torchilin, V. P. (2013). siRNA delivery: from basics to therapeutic applications. Front. Biosci. (Landmark Ed) 18, 58-79. doi: 10.2741/4087 
Musacchio, T., Vaze, O., D’Souza, G., and Torchilin, V. P. (2010). Effective stabilization and delivery of siRNA: reversible siRNA-phospholipid conjugate in nanosized mixed polymeric micelles. Bioconjug. Chem. 21, 1530-1536. doi: $10.1021 /$ bc100199c

Navarro, G., Essex, S., and Torchilin, V. (2013). "The 'Non-viral' approach for siRNA delivery in cancer treatment: a special focus on micelles and liposomes," in DNA and RNA Nanobiotechnologies in Medicine: Diagnosis and Treatment of Diseases, eds V. A. Erdmann and J. Barciszewski (Berlin; Heidelberg: Springer), 241-261. doi: 10.1007/978-3-642-36853-0_10

Nie, S., Xing, Y., Kim, G. J., and Simons, J. W. (2007). Nanotechnology applications in cancer. Annu. Rev. Biomed. Eng. 9, 257-288. doi: 10.1146/annurev.bioeng.9.060906.152025

Oerlemans, C., Bult, W., Bos, M., Storm, G., Nijsen, J. F., and Hennink, W. E. (2010). Polymeric micelles in anticancer therapy: targeting, imaging and triggered release. Pharm. Res. 27, 2569-2589. doi: 10.1007/s11095-0100233-4

Oishi, M., Nagasaki, Y., Itaka, K., Nishiyama, N., and Kataoka, K. (2005). Lactosylated poly(ethylene glycol)-siRNA conjugate through acid-labile betathiopropionate linkage to construct $\mathrm{pH}$-sensitive polyion complex micelles achieving enhanced gene silencing in hepatoma cells. J. Am. Chem. Soc. 127, 1624-1625. doi: 10.1021/ja044941d

Padera, T. P., Stoll, B. R., Tooredman, J. B., Capen, D., Di Tomaso, E., and Jain, R. K. (2004). Pathology: cancer cells compress intratumour vessels. Nature 427, 695. doi: $10.1038 / 427695 a$

Palanca-Wessels, M. C., Convertine, A. J., Cutler-Strom, R., Booth, G. C., Lee, F., Berguig, G. Y., et al. (2011). Anti-CD22 antibody targeting of pH-responsive micelles enhances small interfering RNA delivery and gene silencing in lymphoma cells. Mol. Ther. 19, 1529-1537. doi: 10.1038/mt.2011.104

Park, J. H., Lee, S., Kim, J.-H., Park, K., Kim, K., and Kwon, I. C. (2008). Polymeric nanomedicine for cancer therapy. Prog. Polym. Sci. 33, 113-137. doi: 10.1016/j.progpolymsci.2007.09.003

Pecot, C. V., Calin, G. A., Coleman, R. L., Lopez-Berestein, G., and Sood, A. K. (2011). RNA interference in the clinic: challenges and future directions. Nat. Rev. Cancer 11, 59-67. doi: 10.1038/nrc2966

Peer, D., Karp, J. M., Hong, S., Farokhzad, O. C., Margalit, R., and Langer, R. (2007). Nanocarriers as an emerging platform for cancer therapy. Nat. Nanotechnol. 2, 751-760. doi: 10.1038/nnano.2007.387

Perche, F., Biswas, S., Wang, T., Zhu, L., and Torchilin, V. P. (2014). Hypoxiatargeted siRNA delivery. Angew. Chem. Int. Ed. Engl. 53, 3362-3366. doi: 10.1002/ange. 201308368

Perche, F., Patel, N. R., and Torchilin, V. P. (2012). Accumulation and toxicity of antibody-targeted doxorubicin-loaded PEG-PE micelles in ovarian cancer cell spheroid model. J. Control. Release 164, 95-102. doi: 10.1016/j.jconrel.2012.09.003

Petrenko, V. (2008). Evolution of phage display: from bioactive peptides to bioselective nanomaterials. Expert Opin. Drug Deliv. 5, 825-836. doi: 10.1517/17425247.5.8.825

Petros, R. A., and Desimone, J. M. (2010). Strategies in the design of nanoparticles for therapeutic applications. Nat. Rev. Drug Discov. 9, 615-627. doi: $10.1038 / \mathrm{nrd} 2591$

Plummer, R., Wilson, R. H., Calvert, H., Boddy, A. V., Griffin, M., Sludden, J., et al. (2011). A Phase I clinical study of cisplatin-incorporated polymeric micelles (NC-6004) in patients with solid tumours. Br. J. Cancer 104, 593-598. doi: 10.1038/bjc.2011.6

Prabaharan, M., Grailer, J. J., Steeber, D. A., and Gong, S. (2009). Thermosensitive micelles based on folate-conjugated poly(N-vinylcaprolactam)-blockpoly(ethylene glycol) for tumor-targeted drug delivery. Macromol. Biosci. 9, 744-753. doi: 10.1002/mabi.200800366

Prabhakar, U., Maeda, H., Jain, R. K., Sevick-Muraca, E. M., Zamboni, W., Farokhzad, O. C., et al. (2013). Challenges and key considerations of the enhanced permeability and retention effect for nanomedicine drug delivery in oncology. Cancer Res. 73, 2412-2417. doi: 10.1158/0008-5472.CAN12-4561

Qian, Y., Zha, Y., Feng, B., Pang, Z., Zhang, B., Sun, X., et al. (2013). PEGylated poly(2-(dimethylamino) ethyl methacrylate)/DNA polyplex micelles decorated with phage-displayed TGN peptide for brain-targeted gene delivery. Biomaterials 34, 2117-2129. doi: 10.1016/j.biomaterials.2012.11.050

Qiu, L. Y., Yan, L., Zhang, L., Jin, Y. M., and Zhao, Q. H. (2013). Folatemodified poly(2-ethyl-2-oxazoline) as hydrophilic corona in polymeric micelles for enhanced intracellular doxorubicin delivery. Int. J. Pharm. 456, 315-324. doi: 10.1016/j.ijpharm.2013.08.071

Rana, T. M. (2007). Illuminating the silence: understanding the structure and function of small RNAs. Nat. Rev. Mol. Cell Biol. 8, 23-36. doi: 10.1038/nrm2085

Rapoport, N. (2012). Ultrasound-mediated micellar drug delivery. Int. J. Hyperthermia 28, 374-385. doi: 10.3109/02656736.2012.665567

Rapoport, N., Kennedy, A. M., Shea, J. E., Scaife, C. L., and Nam, K. H. (2010). Ultrasonic nanotherapy of pancreatic cancer: lessons from ultrasound imaging. Mol. Pharm. 7, 22-31. doi: 10.1021/mp900128x

Riehle, R. D., Cornea, S., Degterev, A., and Torchilin, V. (2013). Micellar formulations of pro-apoptotic DM-PIT-1 analogs and TRAIL in vitro and in vivo. Drug. Deliv. 20, 78-85. doi: 10.3109/10717544.2013.766780

Roberts, W. G., and Palade, G. E. (1997). Neovasculature induced by vascular endothelial growth factor is fenestrated. Cancer Res. 57, 765-772.

Saito, G., Swanson, J. A., and Lee, K. D. (2003). Drug delivery strategy utilizing conjugation via reversible disulfide linkages: role and site of cellular reducing activities. Adv. Drug Deliv. Rev. 55, 199-215. doi: 10.1016/S0169409X(02)00179-5

Salzano, G., Riehle, R., Navarro, G., Perche, F., De Rosa, G., and Torchilin, V. P. (2014). Polymeric micelles containing reversibly phospholipid-modified antisurvivin siRNA: a promising strategy to overcome drug resistance in cancer. Cancer Lett. 343, 224-231. doi: 10.1016/j.canlet.2013.09.037

Sarisozen, C., Vural, I., Levchenko, T., Hincal, A. A., and Torchilin, V. P. (2012). Long-circulating PEG-PE micelles co-loaded with paclitaxel and elacridar (GG918) overcome multidrug resistance. Drug. Deliv. 19, 363-370. doi: $10.3109 / 10717544.2012 .724473$

Sashital, D. G., and Doudna, J. A. (2010). Structural insights into RNA interference. Curr. Opin. Struct. Biol. 20, 90-97. doi: 10.1016/j.sbi.2009.12.001

Sawant, R. R., Jhaveri, A. M., Koshkaryev, A., Qureshi, F., and Torchilin, V. P. (2013a). The effect of dual ligand-targeted micelles on the delivery and efficacy of poorly soluble drug for cancer therapy. J. Drug Target. 21, 630-638. doi: 10.3109/1061186X.2013.789032

Sawant, R. R., Jhaveri, A. M., Koshkaryev, A., Zhu, L., Qureshi, F., and Torchilin, V. P. (2013b). Targeted transferrin-modified polymeric micelles: enhanced efficacy in vitro and in vivo in ovarian carcinoma. Mol. Pharm. 11, 375-381. doi: $10.1021 / \mathrm{mp} 300633 \mathrm{f}$

Sawant, R. R., Jhaveri, A. M., and Torchilin, V. P. (2012). Immunomicelles for advancing personalized therapy. Adv. Drug Deliv. Rev. 64, 1436-1446. doi: 10.1016/j.addr.2012.08.003

Sawant, R. R., and Torchilin, V. P. (2010). Multifunctionality of lipid-core micelles for drug delivery and tumour targeting. Mol. Membr. Biol. 27, 232-246. doi: 10.3109/09687688.2010.516276

Schroeder, A., Heller, D. A., Winslow, M. M., Dahlman, J. E., Pratt, G. W., Langer, R., et al. (2012). Treating metastatic cancer with nanotechnology. Nat. Rev. Cancer 12, 39-50. doi: 10.1038/nrc3180

Schumers, J. M., Fustin, C. A., and Gohy, J. F. (2010). Light-responsive block copolymers. Macromol. Rapid Commun. 31, 1588-1607. doi: 10.1002/marc. 201000108

Sharma, A. K., Zhang, L., Li, S., Kelly, D. L., Alakhov, V. Y., Batrakova, E. V., et al. (2008). Prevention of MDR development in leukemia cells by micelle-forming polymeric surfactant. J. Control. Release 131, 220-227. doi: 10.1016/j.jconrel.2008.07.031

Shen, H., Sun, T., and Ferrari, M. (2012). Nanovector delivery of siRNA for cancer therapy. Cancer Gene Ther. 19, 367-373. doi: 10.1038/cgt.2012.22

Shukla, S., Wu, C. P., and Ambudkar, S. V. (2008). Development of inhibitors of ATP-binding cassette drug transporters: present status and challenges. Expert Opin. Drug Metab. Toxicol. 4, 205-223. doi: 10.1517/17425255.4.2.205

Singh, M. (1999). Transferrin As A targeting ligand for liposomes and anticancer drugs. Curr. Pharm. Des. 5, 443-451.

Singh, S., Narang, A. S., and Mahato, R. I. (2011). Subcellular fate and offtarget effects of siRNA, shRNA, and miRNA. Pharm. Res. 28, 2996-3015. doi: 10.1007/s11095-011-0608-1

Skidan, I., Miao, B., Thekkedath, R. V., Dholakia, P., Degterev, A., and Torchilin, V. (2009). In vitro cytotoxicity of novel pro-apoptotic agent DM-PIT-1 in PEG-PEbased micelles alone and in combination with TRAIL. Drug. Deliv. 16, 45-51. doi: 10.1080/10717540802517951

Son, S., Shin, E., and Kim, B. S. (2014). Light-responsive micelles of spiropyran initiated hyperbranched polyglycerol for smart drug delivery. Biomacromolecules 15, 628-634. doi: 10.1021/bm401670t 
Song, N., Ding, M., Pan, Z., Li, J., Zhou, L., Tan, H., et al. (2013). Construction of targeting-clickable and tumor-cleavable polyurethane nanomicelles for multifunctional intracellular drug delivery. Biomacromolecules 14, 4407-4419. doi: 10.1021/bm401342t

Song, W., Tang, Z., Zhang, D., Zhang, Y., Yu, H., Li, M., et al. (2014). Anti-tumor efficacy of $\mathrm{c}$ (RGDfK)-decorated polypeptide-based micelles coloaded with docetaxel and cisplatin. Biomaterials 35, 3005-3014. doi: 10.1016/j.biomaterials.2013.12.018

Spankuch, B., Kurunci-Csacsko, E., Kaufmann, M., and Strebhardt, K. (2007). Rational combinations of siRNAs targeting Plk1 with breast cancer drugs. Oncogene 26, 5793-5807. doi: 10.1038/sj.onc. 1210355

Su, C. W., Chen, S. Y., and Liu, D. M. (2013). Polysaccharide-lecithin reverse micelles with enzyme-degradable triglyceride shell for overcoming tumor multidrug resistance. Chem. Commun. (Camb.) 49, 3772-3774. doi: $10.1039 / \mathrm{c} 3 \mathrm{cc} 40836 \mathrm{a}$

Sudimack, J., and Lee, R. J. (2000). Targeted drug delivery via the folate receptor. Adv. Drug Deliv. Rev. 41, 147-162. doi: 10.1016/S0169-409X(99)00062-9

Suma, T., Miyata, K., Ishii, T., Uchida, S., Uchida, H., Itaka, K., et al. (2012). Enhanced stability and gene silencing ability of siRNA-loaded polyion complexes formulated from polyaspartamide derivatives with a repetitive array of amino groups in the side chain. Biomaterials 33, 2770-2779. doi: 10.1016/j.biomaterials.2011.12.022

Sun, L., Yang, Y., Dong, C. M., and Wei, Y. (2011a). Two-photon-sensitive and sugar-targeted nanocarriers from degradable and dendritic amphiphiles. Small 7, 401-406. doi: 10.1002/smll.201001729

Sun, T. M., Du, J. Z., Yao, Y. D., Mao, C. Q., Dou, S., Huang, S. Y., et al. (2011b). Simultaneous delivery of siRNA and paclitaxel via a "two-in-one" micelleplex promotes synergistic tumor suppression. ACS Nano 5, 1483-1494. doi: 10.1021/nn103349h

Sutton, D., Nasongkla, N., Blanco, E., and Gao, J. (2007). Functionalized micellar systems for cancer targeted drug delivery. Pharm. Res. 24, 1029-1046. doi: 10.1007/s11095-006-9223-y

Taki, H., Kanazawa, T., Akiyama, F., Takashima, Y., and Okada, H. (2012). Intranasal delivery of camptothecin-loaded tat-modified nanomicells for treatment of intracranial brain tumors. Pharmaceuticals (Basel) 5, 1092-1102. doi: $10.3390 /$ ph5101092

Tanaka, K., Kanazawa, T., Horiuchi, S., Ando, T., Sugawara, K., Takashima, Y., et al. (2013). Cytoplasm-responsive nanocarriers conjugated with a functional cellpenetrating peptide for systemic siRNA delivery. Int. J. Pharm. 455, 40-47. doi: 10.1016/j.ijpharm.2013.07.069

Tannock, I. F., and Rotin, D. (1989). Acid pH in tumors and its potential for therapeutic exploitation. Cancer Res. 49, 4373-4384.

Taylor, R. M., and Sillerud, L. O. (2012). Paclitaxel-loaded iron platinum stealth immunomicelles are potent MRI imaging agents that prevent prostate cancer growth in a PSMA-dependent manner. Int. J. Nanomedicine 7, 4341-4352. doi: 10.2147/IJN.S34381

Tong, S. W., Xiang, B., Dong, D. W., and Qi, X. R. (2012). Enhanced antitumor efficacy and decreased toxicity by self-associated docetaxel in phospholipidbased micelles. Int. J. Pharm. 434, 413-419. doi: 10.1016/j.ijpharm.2012. 06.014

Torchilin, V. (2009). Multifunctional and stimuli-sensitive pharmaceutical nanocarriers. Eur. J. Pharm. Biopharm. 71, 431-444. doi: 10.1016/j.ejpb.2008. 09.026

Torchilin, V. (2011). Tumor delivery of macromolecular drugs based on the EPR effect. Adv. Drug Deliv. Rev. 63, 131-135. doi: 10.1016/j.addr.2010.03.011

Torchilin, V. P. (2001). Structure and design of polymeric surfactant-based drug delivery systems. J. Control. Release 73, 137-172. doi: 10.1016/S01683659(01)00299-1

Torchilin, V. P. (2002). PEG-based micelles as carriers of contrast agents for different imaging modalities. Adv. Drug Deliv. Rev. 54, 235-252. doi: 10.1016/S0169409X(02)00019-4

Torchilin, V. P. (2004). Targeted polymeric micelles for delivery of poorly soluble drugs. Cell. Mol. Life Sci. 61, 2549-2559. doi: 10.1007/s00018-004-4153-5

Torchilin, V. P. (2006). Multifunctional nanocarriers. Adv. Drug Deliv. Rev. 58, 1532-1555. doi: 10.1016/j.addr.2006.09.009

Torchilin, V. P. (2007). Micellar nanocarriers: pharmaceutical perspectives. Pharm. Res. 24, 1-16. doi: 10.1007/s11095-006-9132-0

Torchilin, V. P., Lukyanov, A. N., Gao, Z., and Papahadjopoulos-Sternberg, B. (2003). Immunomicelles: targeted pharmaceutical carriers for poorly soluble drugs. Proc. Natl. Acad. Sci. U.S.A. 100, 6039-6044. doi: 10.1073/pnas.0931428100

Torchilin, V. P., and Trubetskoy, V. S. (1995). Which polymers can make nanoparticulate drug carriers long-circulating? Adv. Drug Deliv. Rev. 16, 141-155. doi: 10.1016/0169-409X(95)00022-Y

Valle, J. W., Armstrong, A., Newman, C., Alakhov, V., Pietrzynski, G., Brewer, J., et al. (2011). A phase 2 study of SP1049C, doxorubicin in P-glycoproteintargeting pluronics, in patients with advanced adenocarcinoma of the esophagus and gastroesophageal junction. Invest. New Drugs 29, 1029-1037. doi: 10.1007/s10637-010-9399-1

Varshosaz, J., Sadeghi-Aliabadi, H., Ghasemi, S., and Behdadfar, B. (2013). Use of magnetic folate-dextran-retinoic acid micelles for dual targeting of doxorubicin in breast cancer. Biomed Res. Int. 2013:680712. doi: 10.1155/2013/680712

Wan, C. P., Jackson, J. K., Pirmoradi, F. N., Chiao, M., and Burt, H. M. (2012). Increased accumulation and retention of micellar paclitaxel in drug-sensitive and P-glycoprotein-expressing cell lines following ultrasound exposure. Ultrasound Med. Biol. 38, 736-744. doi: 10.1016/j.ultrasmedbio.2012.01.023

Wang, A. Z., Langer, R., and Farokhzad, O. C. (2012a). Nanoparticle delivery of cancer drugs. Annu. Rev. Med. 63, 185-198. doi: 10.1146/annurev-med-040210162544

Wang, C., Chen, Q., Wang, Z., and Zhang, X. (2010a). An enzyme-responsive polymeric superamphiphile. Angew. Chem. Int. Ed. Engl. 49, 8612-8615. doi: 10.1002/anie.201004253

Wang, C., Ravi, S., Martinez, G. V., Chinnasamy, V., Raulji, P., Howell, M., et al. (2012b). Dual-purpose magnetic micelles for MRI and gene delivery. J. Control. Release 163, 82-92. doi: 10.1016/j.jconrel.2012.04.030

Wang, H.-X., Xiong, M.-H., Wang, Y.-C., Zhu, J., and Wang, J. (2013). $\mathrm{N}$-acetylgalactosamine functionalized mixed micellar nanoparticles for targeted delivery of siRNA to liver. J. Control. Release 166, 106-114. doi: 10.1016/j.jconrel.2012.12.017

Wang, J., Lu, Z., Wientjes, M. G., and Au, J. L. (2010b). Delivery of siRNA therapeutics: barriers and carriers. AAPS J. 12, 492-503. doi: 10.1208/s12248-010-9210-4

Wang, T., Petrenko, V. A., and Torchilin, V. P. (2010c). Paclitaxel-loaded polymeric micelles modified with MCF-7 cell-specific phage protein: enhanced binding to target cancer cells and increased cytotoxicity. Mol. Pharm. 7, 1007-1014. doi: $10.1021 / \mathrm{mp} 1001125$

Wang, X., Li, S., Wan, Z., Quan, Z., and Tan, Q. (2014). Investigation of thermo-sensitive amphiphilic micelles as drug carriers for chemotherapy in cholangiocarcinoma in vitro and in vivo. Int. J. Pharm. 463, 81-88. doi: 10.1016/j.ijpharm.2013.12.046

Wang, Z., Yu, Y., Ma, J., Zhang, H., Wang, X., Wang, J., et al. (2012c). LyP-1 modification to enhance delivery of artemisinin or fluorescent probe loaded polymeric micelles to highly metastatic tumor and its lymphatics. Mol. Pharm. 9, 2646-2657. doi: 10.1021/mp3002107

Watts, J. K., Deleavey, G. F., and Damha, M. J. (2008). Chemically modified siRNA: tools and applications. Drug Discov. Today 13, 842-855. doi: 10.1016/j.drudis.2008.05.007

Wei, H., Zhuo, R.-X., and Zhang, X.-Z. (2012a). Design and development of polymeric micelles with cleavable links for intracellular drug delivery. Prog. Polym. Sci. 38, 503-535. doi: 10.1016/j.progpolymsci.2012.07.002

Wei, X., Wang, Y., Zeng, W., Huang, F., Qin, L., Zhang, C., et al. (2012b). Stability influences the biodistribution, toxicity, and anti-tumor activity of doxorubicin encapsulated in PEG-PE micelles in mice. Pharm. Res. 29, 1977-1989. doi: 10.1007/s11095-012-0725-5

Weiner, L. M. (2007). Building better magic bullets-improving unconjugated monoclonal antibody therapy for cancer. Nat. Rev. Cancer 7, 701-706. doi: $10.1038 / \mathrm{nrc} 2209$

Whitehead, K. A., Langer, R., and Anderson, D. G. (2009). Knocking down barriers: advances in siRNA delivery. Nat. Rev. Drug Discov. 8, 129-138. doi: $10.1038 / \mathrm{nrd} 2742$

Williams, H. D., Trevaskis, N. L., Charman, S. A., Shanker, R. M., Charman, W. N., Pouton, C. W., et al. (2013). Strategies to address low drug solubility in discovery and development. Pharmacol. Rev. 65, 315-499. doi: 10.1124/pr.112.005660

Wu, H., Hait, W. N., and Yang, J. M. (2003). Small interfering RNA-induced suppression of MDR1 (P-glycoprotein) restores sensitivity to multidrug-resistant cancer cells. Cancer Res. 63, 1515-1519.

Wu, H., Zhu, L., and Torchilin, V. P. (2013). pH-sensitive poly(histidine)PEG/DSPE-PEG co-polymer micelles for cytosolic drug delivery. Biomaterials 34, 1213-1222. doi: 10.1016/j.biomaterials.2012.08.072 
Wu, J., Akaike, T., and Maeda, H. (1998). Modulation of enhanced vascular permeability in tumors by a bradykinin antagonist, a cyclooxygenase inhibitor, and a nitric oxide scavenger. Cancer Res. 58, 159-165.

Xing, Y., Wang, C., Han, P., Wang, Z., and Zhang, X. (2012). Acetylcholinesterase responsive polymeric supra-amphiphiles for controlled self-assembly and disassembly. Langmuir 28, 6032-6036. doi: 10.1021/la300612k

Xiong, X. B., and Lavasanifar, A. (2011). Traceable multifunctional micellar nanocarriers for cancer-targeted co-delivery of MDR-1 siRNA and doxorubicin. ACS Nano 5, 5202-5213. doi: 10.1021/nn2013707

Xiong, X. B., Uludag, H., and Lavasanifar, A. (2010). Virus-mimetic polymeric micelles for targeted siRNA delivery. Biomaterials 31, 5886-5893. doi: 10.1016/j.biomaterials.2010.03.075

Xu, W., Burke, J. F., Pilla, S., Chen, H., Jaskula-Sztul, R., and Gong, S. (2013a). Octreotide-functionalized and resveratrol-loaded unimolecular micelles for targeted neuroendocrine cancer therapy. Nanoscale 5, 9924-9933. doi: 10.1039/c3nr03102k

Xu, W., Siddiqui, I. A., Nihal, M., Pilla, S., Rosenthal, K., Mukhtar, H., et al. (2013b). Aptamer-conjugated and doxorubicin-loaded unimolecular micelles for targeted therapy of prostate cancer. Biomaterials 34, 5244-5253. doi: 10.1016/j.biomaterials.2013.03.006

Yang, C., Zhao, H., Yuan, H., Yu, R., and Lan, M. (2013). Preparation and characterization of thermosensitive and folate functionalized Pluronic micelles. J. Nanosci. Nanotechnol. 13, 6553-6559. doi: 10.1166/jnn.2013.7520

Yang, R., Meng, F., Ma, S., Huang, F., Liu, H., and Zhong, Z. (2011). Galactose-decorated cross-linked biodegradable poly(ethylene glycol)b-poly(epsilon-caprolactone) block copolymer micelles for enhanced hepatoma-targeting delivery of paclitaxel. Biomacromolecules 12, 3047-3055. doi: $10.1021 / \mathrm{bm} 2006856$

Yang, X. L., Luo, Y. L., Xu, F., and Chen, Y. S. (2014). Thermosensitive mPEGb-PA-g-PNIPAM comb block copolymer micelles: effect of hydrophilic chain length and camptothecin release behavior. Pharm. Res. 31, 291-304. doi: 10.1007/s11095-013-1160-y

Yin, T., Wang, P., Li, J., Zheng, R., Zheng, B., Cheng, D., et al. (2013). Ultrasoundsensitive siRNA-loaded nanobubbles formed by hetero-assembly of polymeric micelles and liposomes and their therapeutic effect in gliomas. Biomaterials 34, 4532-4543. doi: 10.1016/j.biomaterials.2013.02.067

Yokoyama, M., Miyauchi, M., Yamada, N., Okano, T., Sakurai, Y., Kataoka, K., et al. (1990). Characterization and anticancer activity of the micelleforming polymeric anticancer drug adriamycin-conjugated poly(ethylene glycol)-poly(aspartic acid) block copolymer. Cancer Res. 50, 1693-1700.

Yokoyama, M., Satoh, A., Sakurai, Y., Okano, T., Matsumura, Y., Kakizoe, T., et al. (1998). Incorporation of water-insoluble anticancer drug into polymeric micelles and control of their particle size. J. Control. Release 55, 219-229. doi: 10.1016/S0168-3659(98)00054-6

Yong, D., Luo, Y., Du, F., Huang, J., Lu, W., Dai, Z., et al. (2013). CDDP supramolecular micelles fabricated from adamantine terminated mPEG and beta-cyclodextrin based seven-armed poly (L-glutamic acid)/CDDP complexes. Colloids Surf. B Biointerfaces 105, 31-36. doi: 10.1016/j.colsurfb.2012.12.046

Yu, C., Gao, C., Lu, S., Chen, C., Yang, J., Di, X., et al. (2013a). Facile preparation of $\mathrm{pH}$-sensitive micelles self-assembled from amphiphilic chondroitin sulfatehistamine conjugate for triggered intracellular drug release. Colloids Surf. B Biointerfaces 115C, 331-339. doi: 10.1016/j.colsurfb.2013.12.023

Yu, H., Zou, Y., Wang, Y., Huang, X., Huang, G., Sumer, B. D., et al. (2011). Overcoming endosomal barrier by amphotericin B-loaded dual $\mathrm{pH}$-responsive PDMA-b-PDPA micelleplexes for siRNA delivery. ACS nano 5, 9246-9255. doi: $10.1021 / \mathrm{nn} 203503 \mathrm{~h}$

Yu, J. M., Li, W. D., Lu, L., Zhou, X. Y., Wang, D. Y., Li, H. M., et al. (2014). Preparation and characterization of galactosylated glycol chitosan micelles and its potential use for hepatoma-targeting delivery of doxorubicin. J. Mater. Sci. Mater. Med. 25, 691-701. doi: 10.1007/s10856-013-5109-9

Yu, S. S., Lau, C. M., Barham, W. J., Onishko, H. M., Nelson, C. E., Li, H., et al. (2013b). Macrophage-specific RNA interference targeting via “click," mannosylated polymeric micelles. Mol. Pharm. 10, 975-987. doi: 10.1021/mp300434e

Yuan, F., Chen, Y., Dellian, M., Safabakhsh, N., Ferrara, N., and Jain, R. K. (1996). Time-dependent vascular regression and permeability changes in established human tumor xenografts induced by an anti-vascular endothelial growth factor/vascular permeability factor antibody. Proc. Natl. Acad. Sci. U.S.A. 93, 14765-14770. doi: 10.1073/pnas.93.25.14765
Yuan, F., Dellian, M., Fukumura, D., Leunig, M., Berk, D. A., Torchilin, V. P., et al. (1995). Vascular permeability in a human tumor xenograft: molecular size dependence and cutoff size. Cancer Res. 55, 3752-3756.

Zeng, F., Lee, H., and Allen, C. (2006). Epidermal growth factor-conjugated poly(ethylene glycol)-block- poly(delta-valerolactone) copolymer micelles for targeted delivery of chemotherapeutics. Bioconjug. Chem. 17, 399-409. doi: $10.1021 /$ bc050350g

Zhang, L., Gong, F., Zhang, F., Ma, J., Zhang, P., and Shen, J. (2013). Targeted therapy for human hepatic carcinoma cells using folate-functionalized polymeric micelles loaded with superparamagnetic iron oxide and sorafenib in vitro. Int. J. Nanomedicine 8, 1517-1524. doi: 10.2147/IJN.S43263

Zhang, L., Lu, Z., Zhao, Q., Huang, J., Shen, H., and Zhang, Z. (2011a). Enhanced chemotherapy efficacy by sequential delivery of siRNA and anticancer drugs using PEI-grafted graphene oxide. Small 7, 460-464. doi: 10.1002/smll.201001522

Zhang, W., Shi, Y., Chen, Y., Hao, J., Sha, X., and Fang, X. (2011b). The potential of Pluronic polymeric micelles encapsulated with paclitaxel for the treatment of melanoma using subcutaneous and pulmonary metastatic mice models. Biomaterials 32, 5934-5944. doi: 10.1016/j.biomaterials.2011.04.075

Zhang, W., Shi, Y., Chen, Y., Yu, S., Hao, J., Luo, J., et al. (2010). Enhanced antitumor efficacy by paclitaxel-loaded pluronic P123/F127 mixed micelles against non-small cell lung cancer based on passive tumor targeting and modulation of drug resistance. Eur. J. Pharm. Biopharm. 75, 341-353. doi: 10.1016/j.ejpb.2010.04.017

Zhang, Y., Hong, H., and Cai, W. (2011c). Tumor-targeted drug delivery with aptamers. Curr. Med. Chem. 18, 4185-4194. doi: 10.2174/092986711797189547

Zhao, J., Mi, Y., and Feng, S. S. (2013). Targeted co-delivery of docetaxel and siPlk1 by herceptin-conjugated vitamin E TPGS based immunomicelles. Biomaterials 34, 3411-3421. doi: 10.1016/j.biomaterials.2013.01.009

Zhao, Y. (2007). Rational design of light-controllable polymer micelles. Chem. Rec. 7, 286-294. doi: 10.1002/tcr.20127

Zhao, Y., Duan, S., Zeng, X., Liu, C., Davies, N. M., Li, B., et al. (2012). Prodrug strategy for PSMA-targeted delivery of TGX-221 to prostate cancer cells. Mol. Pharm. 9, 1705-1716. doi: 10.1021/mp3000309

Zhong, Y., Yang, W., Sun, H., Cheng, R., Meng, F., Deng, C., et al. (2013). Liganddirected reduction-sensitive shell-sheddable biodegradable micelles actively deliver doxorubicin into the nuclei of target cancer cells. Biomacromolecules 14, 3723-3730. doi: 10.1021/bm401098w

Zhu, L., Kate, P., and Torchilin, V. P. (2012). Matrix metalloprotease 2-responsive multifunctional liposomal nanocarrier for enhanced tumor targeting. ACS Nano 6, 3491-3498. doi: 10.1021/nn300524f

Zhu, L., Perche, F., Wang, T., and Torchilin, V. P. (2014). Matrix metalloproteinase 2-sensitive multifunctional polymeric micelles for tumor-specific codelivery of siRNA and hydrophobic drugs. Biomaterials 35, 4213-4222. doi: 10.1016/j.biomaterials.2014.01.060

Zhu, L., Wang, T., Perche, F., Taigind, A., and Torchilin, V. P. (2013). Enhanced anticancer activity of nanopreparation containing an MMP2-sensitive PEGdrug conjugate and cell-penetrating moiety. Proc. Natl. Acad. Sci. U.S.A. 110, 17047-17052. doi: 10.1073/pnas.1304987110

Zou, S., Cao, N., Cheng, D., Zheng, R., Wang, J., Zhu, K., et al. (2012). Enhanced apoptosis of ovarian cancer cells via nanocarrier-mediated codelivery of siRNA and doxorubicin. Int. J. Nanomedicine 7, 3823-3835. doi: 10.2147/IJN.S29328

Conflict of Interest Statement: The authors declare that the research was conducted in the absence of any commercial or financial relationships that could be construed as a potential conflict of interest.

Received: 03 March 2014; accepted: 31 March 2014; published online: 25 April 2014. Citation: Jhaveri AM and Torchilin VP (2014) Multifunctional polymeric micelles for delivery of drugs and siRNA. Front. Pharmacol. 5:77. doi: 10.3389/fphar.2014.00077 This article was submitted to Pharmacology of Anti-Cancer Drugs, a section of the journal Frontiers in Pharmacology.

Copyright (c) 2014 Jhaveri and Torchilin. This is an open-access article distributed under the terms of the Creative Commons Attribution License (CC BY). The use, distribution or reproduction in other forums is permitted, provided the original author(s) or licensor are credited and that the original publication in this journal is cited, in accordance with accepted academic practice. No use, distribution or reproduction is permitted which does not comply with these terms. 